ORNL/M-5824

oAK RIDGE

\section{NATIONAL}

LABORATORY
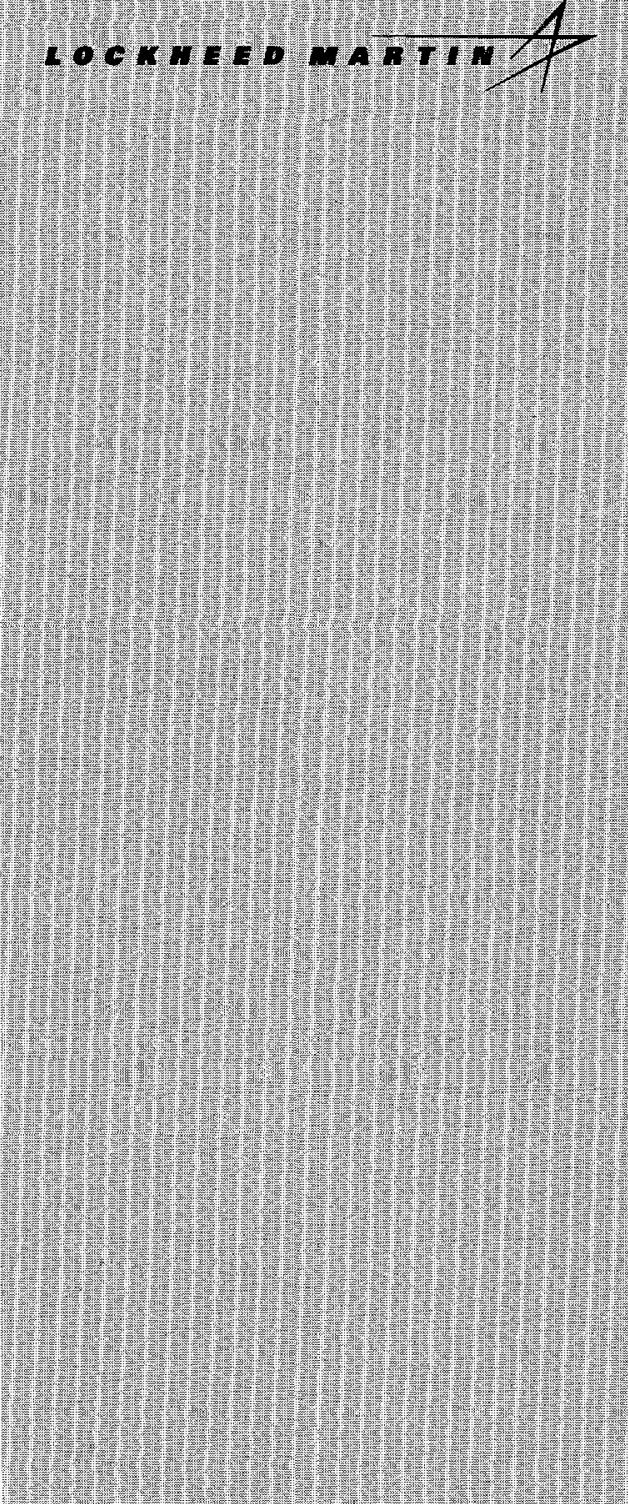

WNAGED AND OPERATED BY

LOCKHEED MABIN ENERGY RESEARCH CORPOBATION FOR THE UNTEO STATES

DEPARTMENT OF ENERGY

\section{Frictional Behavior of Automotive Brake Materials under Wet and Dry Conditions}

\author{
December 15, 1996
}

Final report

Cooperative Research and Development Agreement between

Lockheed Martin Energy Research Corporation and

Ford Motor Company

ORNL 94.0286 
This report has been reproduced directly from the best available copy.

Available to DOE and DOE contractors from the Office of Scientific and Technical Information, P.O. Box 62, Oak Ridge. TN 37831; prices available from (423) 576-8401, FTS 626-8401.

This report was prepared as an account of work sponsored by an agency of the United States Government. Neither the United States Government nor any agency thereof, not any of their employees, makes any warranty, express or implied, or assumes any legal liability or responsibility for the accuracy. completeness, or usefulness of any information, apparatus, product, or process disclosed, or represents that its use would not infringe privately owned rights. Reference herein to any specific commercial product, process, or service by trade name, trademark. manufacturer, or otherwise, does not necessarify constitute or imply its endorsement, recommendation, or favoring by the United States Government or any agency thereof. The views and opinions of authors expressed herein do not necessarily state or reflect those of the United States Government or any agency thereot. 


\section{DISCLAMMER}

Portions of this document may be illegible in electronic image products. Images are produced from the best available original document. 


\title{
Frictional Behavior of Automotive Brake Materials under Wet and Dry Conditions
}

\author{
P. J. Blau and R. L. Martin
}

Metals and Ceramics Division

Oak Ridge National Laboratory

P. O. Box 2008

Oak Ridge, TN 37831-6063

and

M. H. Weintraub, Ho Jang, and W. Donlon

Ford Motor Company

Scientific Research Laboratory

20000 Rotunda Drive

Dearborn, MI 48121-2053

Final Report

Cooperative Research and Development Agreement

ORNL 94-0286

Laboratory Technology Transfer (ERLTT) Program

Office of Energy Research

U.S. Department of Energy

December 15, 1996

Prepared by the

OAK RIDGE NATIONAL LABORATORY managed by

Lockheed Martin Energy Research Corporation

for the U.S. Department of Energy

under Contract No. DE-AC05-96OR22464 


\section{SUMMARY}

This final report is prepared in accordance with Milestone 4 of CRADA ORNL 94-0286 between Lockheed Martin Energy Research Corporation (Oak Ridge National Laboratory) and Ford Motor Company. The dates of performance were September 1, 1994, to December 31, 1995.

I. Objective: The objective of this effort was to develop an improved understanding of the relationship between the structure and frictional behavior of materials in the disc brake/rotor interface with a view toward improving the performance of automotive disc brakes. This was accomplished through microstructural characterization of disc and rotor materials and by conducting wet and dry friction studies in a laboratory apparatus, comparing these results to the partner's data for full-sized rotors and discs.

II. Meeting the Objective: We have developed new surface-extraction techniques for studying the wear mechanisms of brake disc constituents, provided additional information on the micro-abrasive characteristics of pad surfaces, characterized how the nature of transfer films on rotor surfaces depends on interfacial moisture, showed how friction during stopping in wet and dry conditions is affected by such transfer films, and helped establish a reasonable correlation between friction coefficients obtained in simple laboratory experiments and those obtained by much more expensive dynamometer tests. This information improved our mutual understanding of brake materials, thus meeting the objective of the CRADA. An invited, joint ORNL/Ford presentation of these results was made during the Society of Automotive Engineers, 13th Annual Automotive Brake Colloquium, October 1-4, 1995, in Philadelphia, Pennsylvania. The title of that presentation was: "Analysis of the Frictional Variability of Cast Iron Pins Sliding Against Automotive Disc Brake Materials Under Environmentally-Controlled Laboratory Conditions."

III. Benefits to DOE and Defense Programs: Ford Motor Company is a major supplier of automobiles and trucks to both the United States and its allies. In 1995, the company employed over 346,000 people and sold about 6.5 million vehicles. It is a major contributor to the economic health and military readiness of the United States. Like other automotive companies, improving the quality, efficiency, and performance of brakes and friction materials represents a major technological and economic competitive challenge. Developing the knowledge needed to identify improved brake materials can reduce the weight of braking systems and therefore increase vehicle energy efficiency. In addition, the generic nature of friction materials technology will benefit Defense Programs hardware in both transport vehicles and moving mechanical assemblies.

IV. Inventions: This CRADA was a non-proprietary effort and contains no CRADA-protected information. There were no inventions expected or produced as a result of this work.

V. Commercialization Possibilities: As was the original intent, this work provided improved generic knowledge and understanding about the frictional behavior of brake materials, supplementing the partner's on-going research. While it will aid the partner in improving the brake technology base and evaluating potential new brake materials, there is no single commercial product or process which has resulted directly from this work.

VI. Future Collaboration: Since completing work on this CRADA, Ford Motor Company has become a member and active participant in the tribology-related part of the ORNL High Temperature Materials Laboratory User Program. Some of the work begun during this CRADA will serve as a basis for future user projects, and possibly, future CRADAs in the brakes area should funding become available. 


\section{CONTENTS}

1.0 Introduction $\quad$.................................................. 1

2.0 Material Characterization $\quad$................................. 1

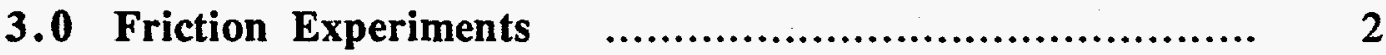

3.1 Test Matrix and Testing Procedures $\quad$............................ 2

3.2 Test Results $\quad$............................................... 4

3.2.1 Effects of Interfacial Moisture on Friction $\quad$........... 4

3.2.2 Experiments in Alternate Wet and Dry Sliding f......... 6

3.2.3 Tests at Three Moisture Levels $\quad \ldots \ldots \ldots \ldots \ldots \ldots \ldots \ldots . \ldots \ldots$

3.2.4 Effects of Repeated Contact on Friction $\quad$.............. 8

3.3 Observations of Contact Surfaces and Transfer Films $\quad \ldots \ldots . . . \quad 10$

4.0 Comparison of Results with Dynamometer Data ............ 11

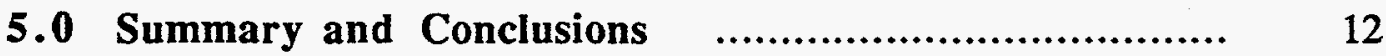

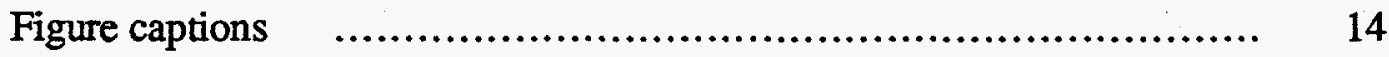

Figures $\quad$........................................................... 15

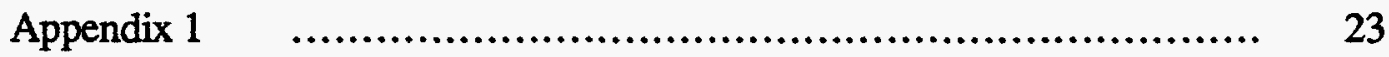

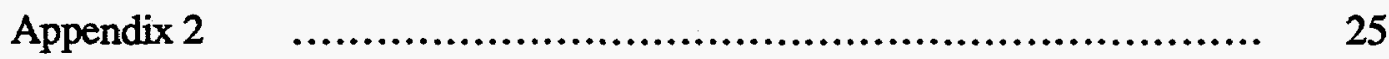

Distribution List $\quad$.......................................................... 42 


\subsection{Introduction}

The purpose of this effort was to develop an improved understanding of the relationship between the structure and frictional behavior of materials in the disc brake/rotor interface with a view toward improving the performance of automotive disc brakes. The three tasks involved in this Cooperative Research and Development Agreement (CRADA) were as follows:

Task 1. Investigation of Brake Pads and Rotors. - Characterize surface features of worn brake pads and rotors, with special attention to the transfer film which forms on them during operation. Ford to supply specimens for examination and other supporting information.

Task 2. Effects of Atmosphere and Repeated Applications on Brake Material Friction. - Conduct pin-on-disk friction tests at ORNL under controlled moisture levels to determine effects of relative humidity on frictional behavior of brake pad and rotor materials. Conduct limited tests on the characteristics of friction under application of repeated contacts.

Task 3. Comparison of Dynamometer Tests with Laboratory Friction Tests. Compare ORNL friction data with Ford dynamometer test data to establish the degree to which the simple bench tests can be useful in helping to understand frictional behavior in full-scale brake component tests.

This final report summarizes work performed under this CRADA.

\subsection{Material Characterization}

Ford provided unused and dynamometer-tested production pad materials and rotors. The following types of characterizations were performed on these materials:

1. Rotor microstructural examination and microindentation hardness tests

2. Microindentation studies of pad materials to survey point-to-point variations

in surface properties

3. Surface roughness measurements of tested rotor surfaces

4. Adhesive extractions of particles from pad material surfaces to assess the bonding of near-surface constituents

5. Wear analysis of dynamometer-tested pads and rotors to identify dominant wear modes

6. Controlled single-point scratch tests of pad and rotor materials to assess the localized abrasion resistance of the materials

Table 1 summarizes the types of wear and material removal processes we observed. Of the wear processes listed in the table, pull-out, transfer, and fracture seem to dominate. Pull-out of whole particles probably results from the fact that many of the constituents are only mechanicallyheld by the resin matrix material and not chemically bonded to it. Even if a bond exists between the outside of the mineral particle and the resin, intraparticle fracture can occur. Those particles exposed at the surface in which the major diameter is at the surface would be the first to leave due to sliding contact. Particles whose major diameters are below the surface of the pad are held more tightly. Thus, they would need to fracture or the surface would have to wear down in order for 
them to become a part of the debris. Metallic constituents and other low-shear strength species in the pads can smear across the surface of adjacent constituents and help to lubricate them while at the same time serving as a weak "glue" to retain them on the surface longer than would otherwise occur under sliding action. The brittle nature of some of the constituents was confirmed by microindentation and scratch tests performed on polished sections of the pad material.

\section{Table 1.}

\section{Wear Processes in Brake Pads}

\begin{tabular}{|l|l|}
\hline \multicolumn{1}{|c|}{ Type of Wear } & \multicolumn{1}{c|}{ Constituent Exhibiting Wear Type } \\
\hline mild abrasive wear & $\begin{array}{l}\text { hard glassy particles, small irregular mineral } \\
\text { chips, and larger mineral plates }\end{array}$ \\
\hline cutting (moderate abrasive) wear & $\begin{array}{l}\text { larger mineral fragments and some matrix } \\
\text { material }\end{array}$ \\
\hline plowing wear & larger areas of resin matrix \\
\hline whole particle pull-out & $\begin{array}{l}\text { some mineral fragments and other constituents } \\
\text { whose removal prevented their exact } \\
\text { identification }\end{array}$ \\
\hline fracture and pull-out & brittle constituents of irregular shape \\
\hline cleavage and delamination & $\begin{array}{l}\text { peeling of mineral layers followed by pull-out } \\
\text { or fracture }\end{array}$ \\
\hline metallic wear with transfer & $\begin{array}{l}\text { shear of ductile materials (coppery-appearing } \\
\text { constituents) and loss by forward and back } \\
\text { transfer to the counterface surface }\end{array}$ \\
\hline
\end{tabular}

\subsection{Friction Experiments}

Friction experiments were conducted on a pin-on-disk machine at Oak Ridge National Laboratory to investigate the effects of ambient environment (moisture) and repeated contact. This section provides a description of those tests and a summary of the main results. The three basic materials combinations used for the tests were cast iron mated with materials designated as Type C, $\mathrm{J}$, and $\mathrm{F}$. Type $\mathrm{C}$ contained $200 \%$ of the normal lubricant and none of the normal abrasive. Type $J$ was the standard composition. Type $F$ contained $200 \%$ of the normal abrasive and none of the normal lubricant.

\subsection{Test Matrix and Testing Procedures}

Initial tests were conducted to establish baseline data to which the effects of variables such as relative humidity and repeated contacts could be compared. All friction tests were conducted using a pin-on-disk tribometer at Oak Ridge National Laboratory (see Fig. 1). At the right side of the apparatus is a remotely-controlled lifting mechanism which could be used to slowly raise or lower the slider holder inside the atmospheric chamber (bell jar) as required. 
Disks were fabricated from $38.1 \mathrm{~mm}$ (1.50 in) diameter circular sections cut from brake pads. Specimens were $6.35 \mathrm{~mm}$ thick. Sliders were machined from actual cast iron rotors. A diagram and digitized image of the dual-bullet-ended slider is shown in Fig. 2. Prior to running a test, each slider was run-in against 220 grit abrasive paper in place of the disk specimen, to produce a flat contact. The dimensions of the initial flat area were obtained using optical photomicrographs (52X), and used to calculate the initial contact pressure. Using a standard normal force of $2.97 \mathrm{~N}$ for our experiments produced contact pressures typical of those seen by brake pads during stops (e.g., 200-400 psi).

After a series of initial trials with various contact conditions, a standard rotation rate of 600 rpm was selected. This rpm was based on achieving the equivalent to 2-5 mph of a Ford Taurus having standard $0.64 \mathrm{~m}$ diameter tires, and assumes that sliding contact occurs at approximately the center of the brake pad. By selecting different wear track radii, it was possible to adjust the sliding speed within the aforementioned range. (See Fig. 3). Friction data were recorded using a highsensitivity, $0.454 \mathrm{kgf}(1.0 \mathrm{lbf}$.) Entran load cell and an Entran power supply and signal amplifier. These were interfaced to a Macintosh IIfx running LabView ${ }^{\mathrm{MM}} 3.0$ software. It was possible to select the number of data/sec, the duration of the sample, and other data acquisition parameters. Baseline tests to establish ambient frictional behavior are described in section 3.2.1.

A series of tests was conducted to establish the repeatability of wet and dry sliding conditions on Type J material. Some were run with no moisture introduced other than that of the lab air. Others we started with the disk wet with distilled water, and others were started with the test wet and with additional distilled water added during the run to keep the track wet. These results are described in Section 3.2.2.

A bell jar could be placed over the entire pin-on-disk apparatus and fed with humidified air through a bubbler system to alter the moisture content in the environment of the sliding contact. By valving off the bubbler, it was possible to introduce dry, breathing air into the jar thereby lowering the relative humidity. Some tests were also conducted with the pads initially covered by a layer of water which spun off when rotation was started. The test matrix is shown in Table 2. Test results are given in Section 3.2.3.

Table 2.

Test Plan for the Effects of Relative Humidity

\begin{tabular}{|c|c|c|c|}
\hline $\begin{array}{c}\text { Pad } \\
\text { Material }\end{array}$ & $\begin{array}{c}\text { Low humidity } \\
\text { level } \\
(<1 \% \mathrm{RH})\end{array}$ & $\begin{array}{c}\text { Intermediate } \\
\text { humidity level } \\
(\sim 65 \% \mathrm{RH})\end{array}$ & $\begin{array}{c}\text { Wet conditions } \\
(100 \% \mathrm{RH})\end{array}$ \\
\hline $\mathrm{C}$ & $\mathrm{X}$ & $\mathrm{X}$ & $\mathrm{X}$ \\
\hline $\mathrm{J}$ & $\mathrm{X}$ & $\mathrm{X}$ & $\mathrm{X}$ \\
\hline $\mathrm{F}$ & $\mathrm{X}$ & $\mathrm{X}$ & $\mathrm{X}$ \\
\hline
\end{tabular}

A second set of experiments was designed to investigate the effects of repetitive application and removal of the normal force on friction under intermediate and wet conditions. Various durations and numbers of applications were used to determine whether the friction force increased, decreased, or remained constant as the contact surface changed by virtue of accumulated sliding distance and the development of transfer layers on the pin and disk surfaces. In one set of tests, a series of short duration $(\sim 1-2 \mathrm{sec})$ contacts was applied. Results and descriptions of the repeated contact tests are given in Section 3.2.4. 


\subsection{Test Results}

Appendix 1 lists data from all friction tests in order of test code (that is, in chronological order). Results and interpretation of specific sets of tests are described in the sections which follow.

3.2.1 Baseline Tests Under Ambient Conditions. Baseline tests corresponding to the intermediate humidity level were conducted. The standard test conditions for these tests were as follows:

\begin{tabular}{|r|l|}
\hline Normal force & $2.97 \mathrm{~N}$ \\
\hline Run-in time for tips on 220 grit paper & $5-10 \mathrm{sec}$ \\
\hline Disk rotation rate & $600 \mathrm{rpm}$ \\
\hline Humidity range & $64 \pm 5 \% \mathrm{RH}$ \\
\hline Atmosphere & laboratory air \\
\hline Ambient temperature & $23 \pm 2^{\circ} \mathrm{C}$ \\
\hline Test duration & $\begin{array}{l}600 \mathrm{sec} \text { ending with a braking, } \\
\text { coast-down phase in which the } \\
\text { motor was stopped with the } \\
\text { normal force still applied }\end{array}$ \\
\hline Data acquisition & $\begin{array}{l}10 \text { sec intervals at a rate of } 100 \\
\text { cts/sec, taken at the start, middle } \\
\text { and end of each test }\end{array}$ \\
\hline
\end{tabular}

Three tests were conducted with each pad material combination. Since each test in the set of three per material was conducted with a different wear track radius, this corresponded to three different velocities of sliding as well. Table 3 lists the conditions for the baseline tests as well as the reference names given friction data files obtained at each portion of the 10 minute tests. Average friction coefficients and the standard deviation in friction coefficient obtained during the mid-point test intervals are given in Table 4.

Table 4 shows that there was no clear difference between the frictional behavior of materials $\mathbf{J}$ and $\mathbf{F}$, but there was a decrease in friction and its variability (standard deviation) exhibited by the type $\mathrm{C}$ material. The friction coefficients of the various sliding combinations were extremely stable at steady state, as evidenced by their standard deviations, roughly corresponding to a typical coefficient of variation (i.e., the standard deviation divided by the average, expressed in percent) of $\sim 0.7 \%$ or less.

We observed no clear effect of sliding velocity on the steady-state friction coefficients of any material combination over the range of testing conditions. Type $C$ material tended to produce the lowest friction coefficients. Examples of the start-up, mid-test, and coast-down phases of a friction test record are given in Fig. 4 (a)-(c). The friction coefficient does not begin at " 0.0 " in the start-up record because the test is started with the load resting on the surface and there is a slight tangential force component imparted when the slider is lowered onto the surface even at rest. The free-hanging slider with no disk contact and no load applied did read " 0.0 ". 
Table 3.

Baseline Tests at Intermediate Relative Humidity Level

(standard contact conditions, relative humidity $=64 \pm 5 \% \mathrm{RH}$ )

\begin{tabular}{|c|c|c|c|c|c|}
\hline $\begin{array}{c}\text { Pad } \\
\text { Material }\end{array}$ & $\begin{array}{c}\text { Starting } \\
\text { Contact } \\
\text { Pressure } \\
\text { (psi) } \\
\end{array}$ & $\begin{array}{c}\text { Vehlcle } \\
\text { speed } \\
\text { equivalent } \\
\text { (mph) } \\
\end{array}$ & $\begin{array}{l}\text { Start-up } \\
\text { friction data } \\
\text { filename }\end{array}$ & $\begin{array}{l}\text { Mid-test } \\
\text { friction data } \\
\text { filename }\end{array}$ & $\begin{array}{l}\text { Coast-down } \\
\text { friction data } \\
\text { filename }\end{array}$ \\
\hline \multirow[t]{3}{*}{ C } & 269.1 & 5.5 & POD-1016 & POD-1017 & POD-1018 \\
\hline & 263.0 & 4.7 & POD-1019 & POD-1020 & POD-1021 \\
\hline & 260.0 & 3.9 & POD-1022 & POD-1023 & POD-1024 \\
\hline \multirow[t]{3}{*}{$J$} & 276.3 & 6.2 & POD-1034 & POD-1035 & POD-1036 \\
\hline & 280.5 & 5.3 & POD-1037 & POD-1038 & POD-1039 \\
\hline & 272.9 & 2.6 & POD-1040 & POD-1041 & POD-1042 \\
\hline \multirow[t]{3}{*}{$\mathbf{F}$} & 269.6 & 5.6 & POD-1025 & POD-1026 & POD-1027 \\
\hline & 267.6 & 4.9 & POD-1028 & POD-1029 & POD-1030 \\
\hline & 265.6 & 4.1 & POD-1031 & POD-1032 & POD-1033 \\
\hline
\end{tabular}

Table 4.

Steady-State Friction Coefficients $(\mu)$ for Baseline Tests at Intermediate Humidity Level

(after 5 minutes of sliding, 998 data points averaged per value)

\begin{tabular}{|c|c|c|}
\hline Pad Material & $\mu_{\text {steady-state }}$ & Std. Deviation in $\mu$ \\
\hline \hline C & 0.251 & 0.0011 \\
& 0.247 & 0.0006 \\
Average of 3 & 0.262 & 0.0013 \\
\hline J & $\underline{0.253}$ & $\underline{0.0010}$ \\
& 0.313 & 0.0014 \\
& 0.279 & 0.0022 \\
Average of 3 & 0.333 & 0.0020 \\
F & $\underline{0.308}$ & $\underline{0.0019}$ \\
& 0.290 & 0.0015 \\
& 0.340 & 0.0016 \\
Average of 3 & 0.307 & 0.0017 \\
\end{tabular}




\subsubsection{Experiments in Alternate Wet and Dry Sliding}

Pin-on-disk tests were performed on Type $J$ material to investigate the effects of alternate fully-flooded and dry cycles on the frictional characteristics. In all cases, tests in this series were started with the pin in contact under the $2.97 \mathrm{~N}$ normal load, allowed to run at $600 \mathrm{rpm}$ for about 12 seconds, and allowed to coast to a stop with the motor turned off. Distilled water was used in all the wet-condition tests. The starting, run-in contact area of the pin specimen was $1.56 \mathrm{~mm}^{2}$, corresponding to a contact pressure of $1.90 \mathrm{MPa}$. The tests are summarized in Table 5 below.

Table 5.

Wet and Dry Tests of Type J Material

(2.97 N load, $600 \mathrm{rpm}, 58-63 \%$ ambient $\mathrm{RH}$ )

\begin{tabular}{|c|l|l|c|}
\hline Sequence & \multicolumn{1}{|c|}{ Slider } & \multicolumn{1}{|c|}{ Procedure } & Test Code \\
\hline \hline 1 & $\begin{array}{l}\text { cast-Fe worn-in fresh on } \\
220 \text { grit dry abrasive } \\
\text { paper }\end{array}$ & $\begin{array}{l}\text { start immersed and continue to supply } \\
\text { water during the run until the motor was } \\
\text { stopped and coast-down occurred }\end{array}$ & POD-1043 \\
\hline 2 & $\begin{array}{l}\text { same pin as for the } \\
\text { previous run }\end{array}$ & $\begin{array}{l}\text { start immersed and continue to supply } \\
\text { water during the run until the motor was } \\
\text { stopped and coast-down occurred }\end{array}$ & POD-1044 \\
\hline 3 & $\begin{array}{l}\text { same pin as for the } \\
\text { previous run }\end{array}$ & $\begin{array}{l}\text { start immersed, but add no additional } \\
\text { water for the duration of the run }\end{array}$ & POD-1045 \\
\hline 4 & $\begin{array}{l}\text { same pin as for the } \\
\text { previous run }\end{array}$ & $\begin{array}{l}\text { dry disk thoroughly under a hot air blower } \\
\text { for } 5 \text { minutes, allow to stand for 15 } \\
\text { minutes, then run dry }\end{array}$ & POD-1046 \\
\hline 5 & $\begin{array}{l}\text { same pin as for the } \\
\text { previous run }\end{array}$ & $\begin{array}{l}\text { start immersed, but add no additional } \\
\text { water for the duration of the run }\end{array}$ & POD-1047 \\
\hline
\end{tabular}

Frictional behavior of the first two tests in the sequence was extremely repeatable. The friction coefficient began with a slight peak $(\mu=0.25 \pm 0.01)$, fell briefly to a minimum $(\mu \approx 0.23)$, and then rose gradually until the motor was turned off at which time there was a sharp rise $(\mu>$ 0.4). The third test was started with the disk wet, but no additional water was supplied. Similar behavior was observed with the exception that the maximum friction coefficient during coast-down and stop was somewhat lower $(\mu \approx 0.35)$. The fourth test in the series revealed that when the disk was dried, a different frictional behavior occurred. It rose initially to a higher value than the waterlubricated tests $(\mu=0.33)$, then dipped briefly to slightly less than $\mu=0.32$, and rose to what appeared to be a steady-state level $(\mu \approx 0.34)$ before falling off during the coast-down period. There was no sharp rise, as in the previous three tests. The last test in the series demonstrated that the behavior of the third run could be regained nearly exactly by starting in the immersed condition as before. Figure 5 (a)-(d) shows test records for the last runs $2-5$ in the sequence. The friction trace for the first run in the series looked very much like the second run and was not shown. 


\subsubsection{Tests at three moisture levels.}

Sliding tests were conducted under three moisture levels to establish its effect on the frictional behavior of the three brake pad compositions: (1) normal humidity $(\sim 60 \% \mathrm{RH}),(2)$ wet $(100 \% \mathrm{RH})$, and (3) very dry $(<1 \% \mathrm{RH})$. Standard conditions were: $2.97 \mathrm{~N}$ load, run-in cast-Fe pin tips, and $600 \mathrm{rpm}$ disk rotational speed. There were three tests run per condition. The friction coefficients for each condition, measured at 10 seconds after the start of sliding, are given in Table 6 and represented graphically in Fig. 6.

Table 6.

Effects of Relative Humidity on Friction Coefficient

(average of 3 values measured after $10 \mathrm{~s}$ of sliding, rounded to 2 decimal places)

\begin{tabular}{|c|c|c|c|}
\hline $\begin{array}{c}\text { Disk } \\
\text { Material }\end{array}$ & $\begin{array}{c}\text { Low humidity } \\
\text { level } \\
(<1 \% \mathrm{RH})\end{array}$ & $\begin{array}{c}\text { Intermediate } \\
\text { humidity level } \\
(63 \pm 4 \% \mathrm{RH})\end{array}$ & $\begin{array}{c}\text { Wet conditions } \\
(100 \% \mathrm{RH})\end{array}$ \\
\hline \hline C & 0.35 & 0.24 & 0.22 \\
\hline $\mathrm{J}$ & 0.33 & 0.25 & 0.26 \\
\hline F & 0.26 & 0.25 & 0.31 \\
\hline $\begin{array}{c}\text { Range over } \\
\text { all three } \\
\text { materials }\end{array}$ & 0.09 & 0.01 & 0.09 \\
\hline
\end{tabular}

Several trends are obvious from these data:

1. The average friction coefficients for all three disk materials were similar after $10 \mathrm{~s}$ of sliding at the intermediate humidity level, but they deviated significantly under both dry and wet conditions.

2. The high-lubricant, low abrasive composition (C) had the highest friction of all three materials under dry conditions, but the lowest friction of all three materials under wet conditions. This suggests that for the given lubricant to function properly, some moisture must be present. Such behavior is not unique in tribology. In fact, solid lubricants such as graphite work much better in the presence of moisture; whereas, solid lubricants such as molybdenum disulfide work better in vacuum or without the presence of moisture.

3. The high-abrasive, low-lubricant material (F) had the highest friction under wet conditions. However, it had the lowest friction under dry conditions. If the abrasive action enhanced wear particle generation under dry conditions, it is possible that the wear particles formed a layer which acted as a powdered lubricant to reduce friction. The latter hypothesis needs to be studied further and validated under controlled experimental conditions.

The above data, which were obtained after a specific time of sliding (i.e., 10 s), should not be considered the complete story when attempting to evaluate moisture effects on braking behavior. Rather, it is necessary to consider other aspects of the frictional behavior such as the shapes of the friction curves during coast-down, as indicated in 3.2.3, above. Furthermore, it is likely that the effects of moisture on frictional behavior would probably be quite different if the brake pads and rotors were hot from use. 


\subsubsection{Effects of Repeated Contact on Friction}

Friction tests were conducted under wet and dry conditions to determine whether the friction behavior changed with repeated application of the normal force. In each test, the normal force was applied and retracted between five and ten times for approximately 1.5 seconds at a time. The average friction coefficient per application and the general shape (i.e., rising, steady, or falling) of the individual application was noted.

Table 7 summarizes the results of tests conducted at four different values of normal force in air. There was no obvious influence of the normal force on average friction under these test conditions. Furthermore, there was no obvious pattern as to whether the friction force rose or fell after a set number of contacts. Rises did tend to outnumber other types of behavior, however.

Table 7.

Repeated Contact Tests Under Dry Conditions on Type J Material

\begin{tabular}{|c|c|c|c|c|}
\hline Test Number & $\begin{array}{c}\text { Normal Force } \\
(\mathbf{N})\end{array}$ & Contact \# & $\begin{array}{c}\text { Steady-state } \\
(\text { Note 1) }\end{array}$ & $\begin{array}{c}\text { Trend } \\
\text { (Note 2) }\end{array}$ \\
\hline \hline POD-1054 & 0.99 & 1 & 0.20 & $\mathrm{~S}$ \\
\hline & & 2 & 0.19 & $\mathrm{R}$ \\
\hline & & 3 & 0.19 & $\mathrm{R}$ \\
\hline & & 4 & 0.17 & $\mathrm{R}$ \\
\hline & & 5 & 0.21 & $\mathrm{R}$ \\
\hline & & ave. (std. dev.) & $\mathbf{0 . 1 9 ( 0 . 0 1 )}$ & $\mathrm{R}$ \\
\hline POD-1055 & 1.99 & 1 & 0.19 & $\mathrm{R}$ \\
\hline & & 2 & 0.20 & $\mathrm{R}$ \\
\hline & & 3 & 0.24 & $\mathrm{~S}$ \\
\hline & & 4 & 0.20 & $\mathrm{R}$ \\
\hline & & 5 & 0.25 & $\mathrm{~S}$ \\
\hline & & ave. (std. dev.) & $0.22(0.03)$ & \\
\hline POD-1056 & 2.97 & 1 & 0.26 & $\mathrm{~F}$ \\
\hline & & 2 & 0.24 & $\mathrm{R}$ \\
\hline & & 3 & 0.24 & $\mathrm{R}$ \\
\hline & & 4 & 0.25 & $\mathrm{R}$ \\
\hline & & 5 & 0.27 & $\mathrm{~F}$ \\
\hline & & ave. (std. dev.) & $0.25(0.01)$ & \\
\hline POD-1057 & 3.97 & 1 & 0.21 & slight R \\
\hline & & 2 & 0.23 & $\mathrm{~F}$ \\
\hline & & 3 & 0.20 & $\mathrm{R}$ \\
\hline & & 4 & 0.22 & $\mathrm{~S}$ \\
\hline & & 5 & 0.21 & $\mathrm{R}$ \\
\hline & & ave. (std. dev.) & $\mathbf{0 . 2 1}(0.01)$ & \\
\hline & & & & \\
\hline
\end{tabular}

Notes:

(1) Averaged over the $\approx 1.5$ second contact time

(2) Shape of the friction vs. time plot: $R=$ rising, $F=$ falling, $S=$ steady

We also conducted repeated contact tests under wet conditions to determine whether there might be differences in response among the three types of pad materials with water in the interface. Tests were run beginning with a puddle of distilled water on the surface of the disk. Most of the 
water spun off during operation, however, the surfaces still appeared dark and moist when disk rotation came to a stop. Tables $8(\mathrm{a}-\mathrm{c})$ summarize these results.

Table 8 (a).

Repeated Contact Tests Under Wet Conditions on Type J Material (water introduced at the start, no additional water added)

\begin{tabular}{|c|c|c|c|c|}
\hline Test Number & $\begin{array}{l}\text { Normal Force } \\
(\mathbf{N})\end{array}$ & Contact \# & $\begin{array}{c}\text { Steady-state } \mu \\
\text { (Note 1) }\end{array}$ & $\begin{array}{l}\text { Trend } \\
\text { (Note 2) }\end{array}$ \\
\hline POD-1067 & 2.97 & 1 & 0.14 & $\overline{\mathbf{R}}$ \\
\hline & & 2 & 0.13 & $\overline{\mathbf{R}}$ \\
\hline & & 3 & 0.15 & slight $\mathbf{R}$ \\
\hline & & 4 & 0.14 & $\mathbf{R}$ \\
\hline & & 5 & 0.16 & $\bar{F}$ \\
\hline & & ave. (std. dev.) & $0.14(0.01)$ & \\
\hline POD-1068 & 2.97 & 1 & 0.15 & $\mathbf{R}$ \\
\hline & & 2 & 0.15 & $\overline{\mathbf{R}}$ \\
\hline & & 3 & 0.18 & $\overline{\mathrm{F}}$ \\
\hline & & $\overline{4}$ & 0.14 & $\overline{\mathrm{R}}$ \\
\hline & & 5 & 0.15 & $\overline{\mathbf{R}}$ \\
\hline & & ave. (std. dev.) & $0.15(0.02)$ & \\
\hline
\end{tabular}

Notes:

(1) Averaged over the $\approx 1.5$ second contact time

(2) Shape of the friction vs. time plot: $R=$ rising, $F=$ falling, $S=$ steady

Table 8 (b).

Repeated Contact Tests Under Wet Conditions on Type C Material (water introduced at the start, no additional water added)

\begin{tabular}{|c|c|c|c|c|}
\hline Test Number & $\begin{array}{c}\text { Normal Force } \\
\text { (N) }\end{array}$ & Contact \# & $\begin{array}{c}\text { Steady-state } \mu \\
\text { (Note 1) }\end{array}$ & $\begin{array}{l}\text { Trend } \\
\text { (Note 2) }\end{array}$ \\
\hline \multirow[t]{6}{*}{ POD-1072 } & 2.97 & 1 & 0.22 & $\mathrm{~S}$ \\
\hline & & 2 & 0.20 & $\overline{\mathbf{R}}$ \\
\hline & & 3 & 0.22 & $\mathbf{R}$ \\
\hline & & 4 & 0.23 & $\bar{S}$ \\
\hline & & 5 & 0.23 & $\mathbf{S}$ \\
\hline & & ave. (std. dev.) & $0.22(0.01)$ & - \\
\hline \multirow[t]{6}{*}{ POD-1073 } & 2.97 & 1 & 0.17 & $\mathbf{R}$ \\
\hline & & 2 & 0.20 & $\bar{R}$ \\
\hline & & 3 & 0.19 & $\mathbf{R}$ \\
\hline & & 4 & 0.21 & $\overline{\mathbf{R}}$ \\
\hline & & 5 & 0.20 & $\overline{\mathbf{R}}$ \\
\hline & & ave. (std. dev.) & $0.20(0.02)$ & \\
\hline
\end{tabular}

Notes:

(1) Averaged over the $\approx 1.5$ second contact time

(2) Shape of the friction vs. time plot: $R=$ rising, $F=$ falling, $S=$ steady

For type J material, average friction coefficients in the wet case were about $60 \%$ of those observed under the same normal load for the ambient air case. Again, rises tended to outnumber 
falls or steady friction behavior, and the surface of the pin tips grew progressively smoother, the longer the total sliding distance.

For type $\mathrm{C}$ and type $\mathrm{F}$ materials, the average friction coefficients for each contact were higher than those of type $\mathrm{J}$, but it must be remembered that these are values from very short term tests and do not account for the affects of elevated temperature or prolonged contact. Type $F$ material had the highest friction coefficients observed during the repeated contact tests in water, however, these were not nearly as high as the transients observed during the coast-down experiments described earlier.

Table 8 (c).

Repeated Contact Tests Under Wet Conditions on Type F Material (water introduced at the start, no additional water added)

\begin{tabular}{|c|c|c|c|c|}
\hline Test Number & $\begin{array}{c}\text { Normal Force } \\
(\mathbf{N})\end{array}$ & Contact \# & $\begin{array}{c}\text { Steady-state } \mu \\
\text { (Note 1) }\end{array}$ & $\begin{array}{c}\text { Trend } \\
\text { (Note 2) }\end{array}$ \\
\hline \hline POD-1074 & 2.97 & 1 & 0.25 & $\mathrm{R}$ \\
\hline & & 2 & 0.26 & $\mathrm{R}$ \\
\hline & & 3 & 0.27 & $\mathrm{R}$ \\
\hline & & 4 & 0.27 & $\mathrm{R}$ \\
\hline & & 5 & 0.27 & $\mathrm{R}$ \\
\hline POD-1075 & 2.97 & 1 & $0.26(0.01)$ & $\mathrm{R} / \mathrm{F}$ \\
\hline & & 2 & 0.22 & $\mathrm{R}$ \\
\hline & & 3 & 0.26 & $\mathrm{R}$ \\
\hline & & 4 & 0.25 & $\mathrm{R}$ \\
\hline & & 5 & 0.26 & $\mathrm{R}$ \\
\hline & & ave. (std. dev.) & 0.26 & $\mathbf{0 . 2 5}(0.02)$ \\
\hline
\end{tabular}

Notes:

(1) Averaged over the $\approx 1.5$ second contact time

(2) Shape of the friction vs. time plot: $\mathrm{R}=$ rising, $\mathrm{F}=$ falling, $\mathrm{S}=$ steady

Overall, it can be concluded that for short, repeated applications of the normal force:

1. Friction forces generally rose over the period of force application

2 There were no obvious tendencies for the average friction coefficient to either rise or fall over the course of the five repeated applications of contact.

3. Type F material exhibited the highest friction coefficients during the repeated contact tests.

4. On Type J material, the wet repeated contact tests gave friction coefficients about $60 \%$ lower than the dry repeated contact tests.

\subsection{Observations of Contact Surfaces and Transfer Films}

Examination of slider tips indicated that the actual contact which experienced wear was less than the run-in area used to calculate the starting pressure. Using a digitizing tablet, post-test photomicrographs of slider tips were digitized to determine the estimated fraction of the run-in (starting) tip that was actually in contact. In general, it was found that the actual sliding contact areas were approximately one half to three-quarters the size of the abraded, run-in areas on the ball 
tips, therefore, the contact pressures in many of these tests were approximately 1.5 to 2.0 times those calculated from the initial scar size (as-abraded).

Energy-dispersive X-ray analysis (EDXA) was conducted on cast-iron pin tips run under wet conditions and under ambient air conditions to determine whether the qualitative observations about the absence of transfer films under wet sliding conditions could be verified by differences in sliding surface composition (Test codes POD-1069 and POD-1071). An accelerating voltage of 15 $\mathrm{kV}$ was used with worn pin tips which were cut off with a diamond wafer saw and mounted facing up on standard SEM stubs. Figure 7 (a) shows a typical EDXA spectrum for a $100 \times 100 \mu \mathrm{m}$ square region on a pin tip run in water. The primary peaks are $\mathrm{Fe}$ and $\mathrm{Si}$. A minor peak, possibly representing $O$, is present at the extreme left end of the spectrum. Figure 7 (b) is typical of those taken from a deposit of particles clinging to the pin tip which was run in air (Fig. 8). The additional elements $\mathrm{Cu}, \mathrm{Al}, \mathrm{S}, \mathrm{Cl}, \mathrm{K}, \mathrm{Ca}$, and $\mathrm{Ti}$ are believed to come from the transferred material picked up from the disk. These results are consistent with the optical microscope indications that running in the presence of water tended to reduce the tendency for the disk material to develop transfer layers.

\subsection{Comparison of Results with Dynamometer Data}

Ho Jang, Ford SRL, provided information on the testing of the same materials as described herein in dynamometer trials at Ford. In general, the pin-on-disk friction coefficients for 5 minutes of sliding at intermediate humidity, among the longer of the tests we conducted, were about 17 to $25 \%$ lower than those obtained in dynamometer tests, as shown in Table 9 (a). The low-humidity runs (Table 6) had among the highest friction coefficients we measured and even these were lower than those reported for the dynamometer tests.

Table 9 (a).

Comparison of Pin-on-Disk Friction Data with Dynamometer Data

\begin{tabular}{|c|c|c|}
\hline Pad Material Type & $\begin{array}{c}\text { Pin-on-Disk } \\
\text { Ave. } \mu_{\mathrm{dry}} \\
\text { (Note 1) }\end{array}$ & $\begin{array}{c}\text { Dynamometer } \\
\text { Ave. } \mu \\
\text { (Note 2) }\end{array}$ \\
\hline \hline $\mathrm{J}$ & 0.308 & 0.37 \\
\hline $\mathrm{C}$ & 0.253 & 0.34 \\
\hline $\mathrm{F}$ & 0.312 & 0.39 \\
\hline
\end{tabular}

Note 1: Table 4 data.

Note 2: read from bar chart in report provided by Ford.

The relative differences between the three pad materials compared in Table 9 (a) are given in Table 9 (b). As shown, the relative rankings and differences between compositions are qualitatively similar even if the magnitudes of the data are not. Considering the significant differences between the mechanics and thermal conditions experienced in brake dynamometer testing and the simple pin-on-disk testing, the results compare rather well.

Comparing pin-on-disk test results to dynamometer friction data, we find that the friction coefficients were not equal even when using equivalent sliding material combinations. However, the pin-on-disk test should not be totally discounted because the present tests were of relatively short duration and did not use the same surface speeds. In addition, longer runs would have permitted additional build-up of transfer films and these may have increased the steady-state 
friction. Heat build-up and other factors would also tend to reduce the degree of agreement between the two types of tests.

Based on these findings, the pin-on-disk test would probably not be the bench-scale test of choice for pad material screening; however, it did permit us to show significant differences in frictional transients during stopping under wet and dry conditions and did demonstrate the importance of relative humidity on frictional performance of cast-iron on resin-based pad materials.

Table 9 (b).

Comparison of Pin-on-Disk Friction Data with Dynamometer Data

\begin{tabular}{|c|c|c|}
\hline Pad Material Type & $\begin{array}{c}\text { Pin-on-Disk } \mu \\
\text { relative to J }\end{array}$ & $\begin{array}{c}\text { Dynamometer } \mu \\
\text { relative to J }\end{array}$ \\
\hline \hline $\mathrm{J}$ & 1.00 & 1.00 \\
\hline $\mathrm{C}$ & 0.82 & 0.92 \\
\hline $\mathrm{F}$ & 1.01 & 1.05 \\
\hline
\end{tabular}

\subsection{Summary}

This summary contains the results of the first portion of this work (see Appendix 2 which summarizes the earlier work) in addition to the results described here.

Studies of brake pads (new and dynamometer-tested) and rotors (dynamometer-tested) produced the following findings:

1. Pad materials are very heterogeneous in composition and microindentation hardness and thus produced a variety of responses to sliding contact. Wear of the pad materials occurs differently for individual constituents within the material ranging from light abrasion of the hard phases to adhesive pull-out, cleavage, and complete loss of the soft, loosely-bound phases. A spectrum of wear modes exists on the same surface. In fact, even a small area of the pad contact surface can exhibit a range of wear processes and mechanisms, all of which probably operate simultaneously.

2. Adhesive extractions of worn pads indicate considerable loose material on the surface. This easily removed material, usually taking the form of discrete particles, can occupy $20-30 \%$ of the contact area.

3. Scratch tests with a diamond indenter indicated that the abrasion resistance and the cutting and plowing contributions to friction vary widely from place-to-place on the contact surface of the brake pads. There is much less variation of scratching force and scratch width on the polished rotor surface. Evidence for the extrusion of graphite flakes was observed. A distribution of values of tangential force was obtained for both pad and rotor materials. The wide variation in tangential force for the pad material would not be expected during normal operation because the combined contributions of many individual contacts would be averaged out over the entire nominal contact area of the pad surface.

4. Various measures of surface roughness were used to evaluate the faces of the rotors. $R_{a}$ and $R_{q}$ did not vary significantly between the non-contact and the rubbing areas of the rotor faces, but there was an increase in $R_{t}$, delQ, and kurtosis 
in the worn areas. More extensive data are needed to establish whether any or all of the latter measures of surface roughness will be useful in studying rotor wear.

5. Transfer layers were visible in scanning electron micrographs of the rotor surfaces, but they did not appear continuous over large areas. Rather, they appeared as small localized patches of compressed particulate material. In some cases, they were subjected to fragmentation around the margins of the patches, and at least in one instance, it appeared that a section of the transfer patch may have been pulled out leaving a rounded opening.

Pin-on-disk friction tests for cast iron pins sliding on the three brake pad materials were performed at speeds equivalent to approximately $2-5$ miles per hour. The materials were provided by Ford. Results indicated the following:

1. The friction coefficients measured during pin-on-disk tests were generally lower than those observed in dynamometer tests, but relative differences between pad compositions tested under ambient conditions were qualitatively similar.

2. There was a significant effect of relative humidity on the steady-state friction coefficient of all three pad compositions. This was indicated not only by the magnitude of the steady state friction coefficients, but more directly by the frictiontime behavior of the sliding couple when the motor was turned off and the disk coasted to a stop.

3. Wet sliding tended to suppress the formation of transfer films on the cast iron slider tips. This was observed by visual examination and by energy-dispersive analysis. The absence of the transfer films may have been a contributing factor for the friction spike recorded during coast-down tests run in wet conditions. The other possible cause is the disruption of the friction-reducing, partial-hydrodynamic film when the sliding speed decreased to zero. The friction spike was preceded by a series of stages in which friction force increased linearly, then dwelled prior to stopping, and finally, rose to a peak just at the point of stopping.

Overall, we conclude that the laboratory characterizations performed during this CRADA helped to elucidate the effects of moisture on the formation of transfer films and the development of friction transients experienced during the sliding of brake-rotor material combinations. We believe that the information will contribute to the understanding of certain phenomena observed during the operation of actual braking systems under wet and dry conditions. 


\section{Figure Captions.}

Figure 1. The pin-on-disk machine used in these tests (bell jar removed). The fixture at right was designed to permit one to raise and lower the slider when the bell jar was in place.

Figure 2. Double-ended cast iron slider specimen (the pin). The bullet-ends were run-in on abrasive paper to produce a flat spot for testing.

Figure 3. Speed range for pin-on-disk tests. Family of curves for various track diameters on the pin-on-disk machine.

Figure 4. Phases of a typical friction test: (a) start-up, (b) mid-test, (c) coast-down.

Figure 5. Series of tests run under wet and dry conditions.

Figure 6. Effects of relative humidity on friction coefficient.

Figure 7. EDXA spectrum of pin tips (a) run wet, and (b) run in air.

Figure 8. Scanning electron micrograph of a pin slid in air. 


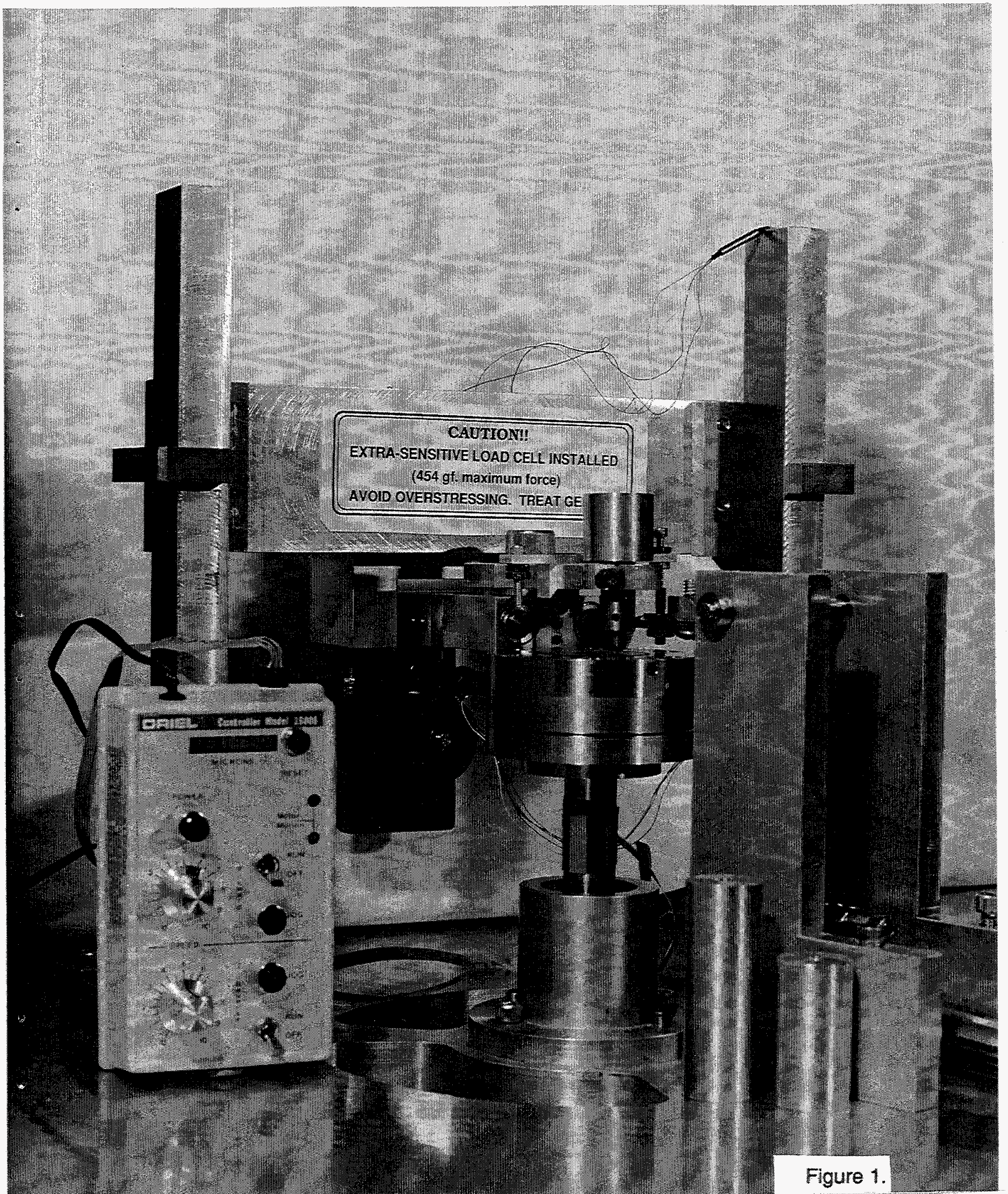




\section{TEST PINS WERE FABRICATED FROM CAST IRON ROTORS}

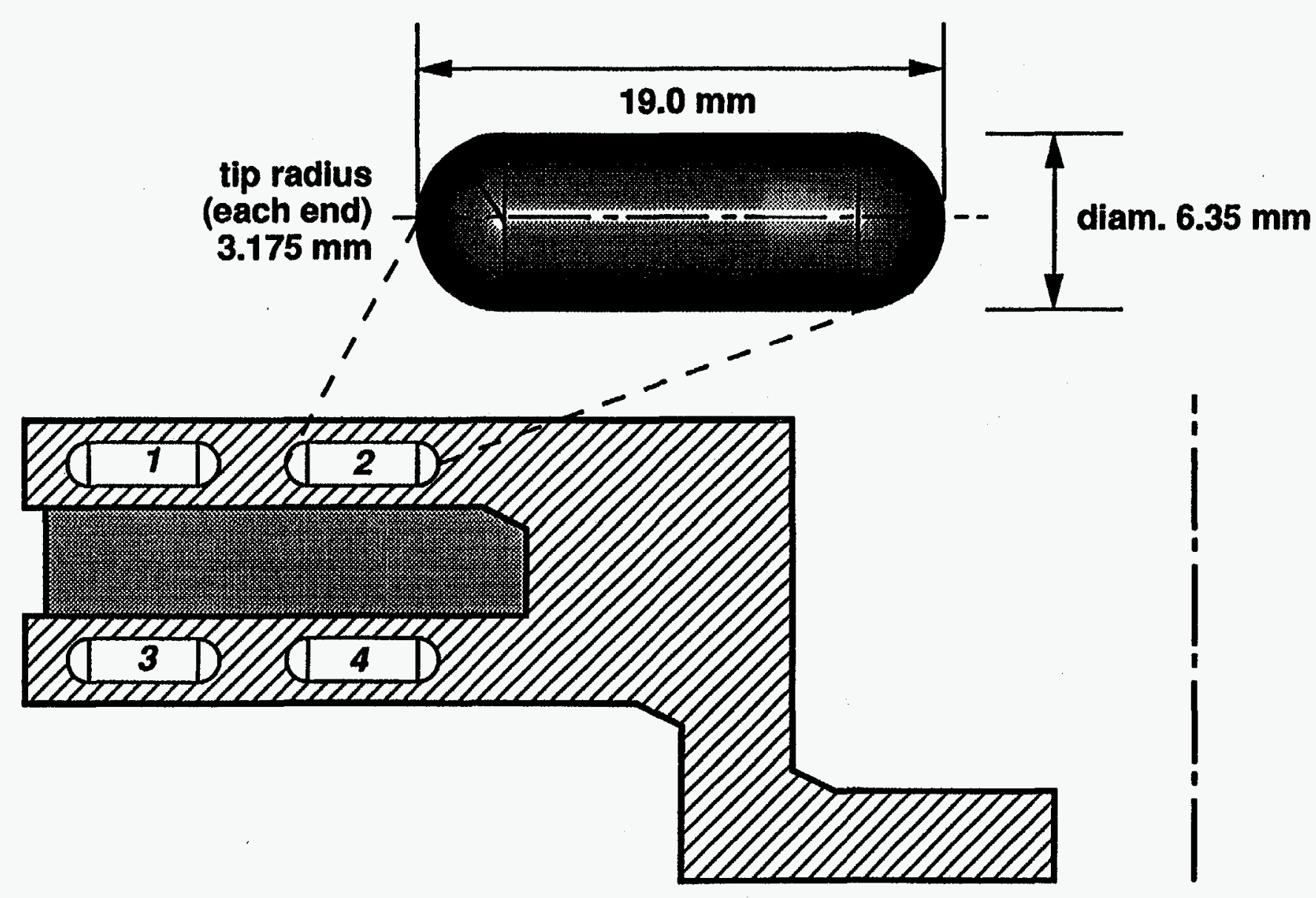

Figure 2. 


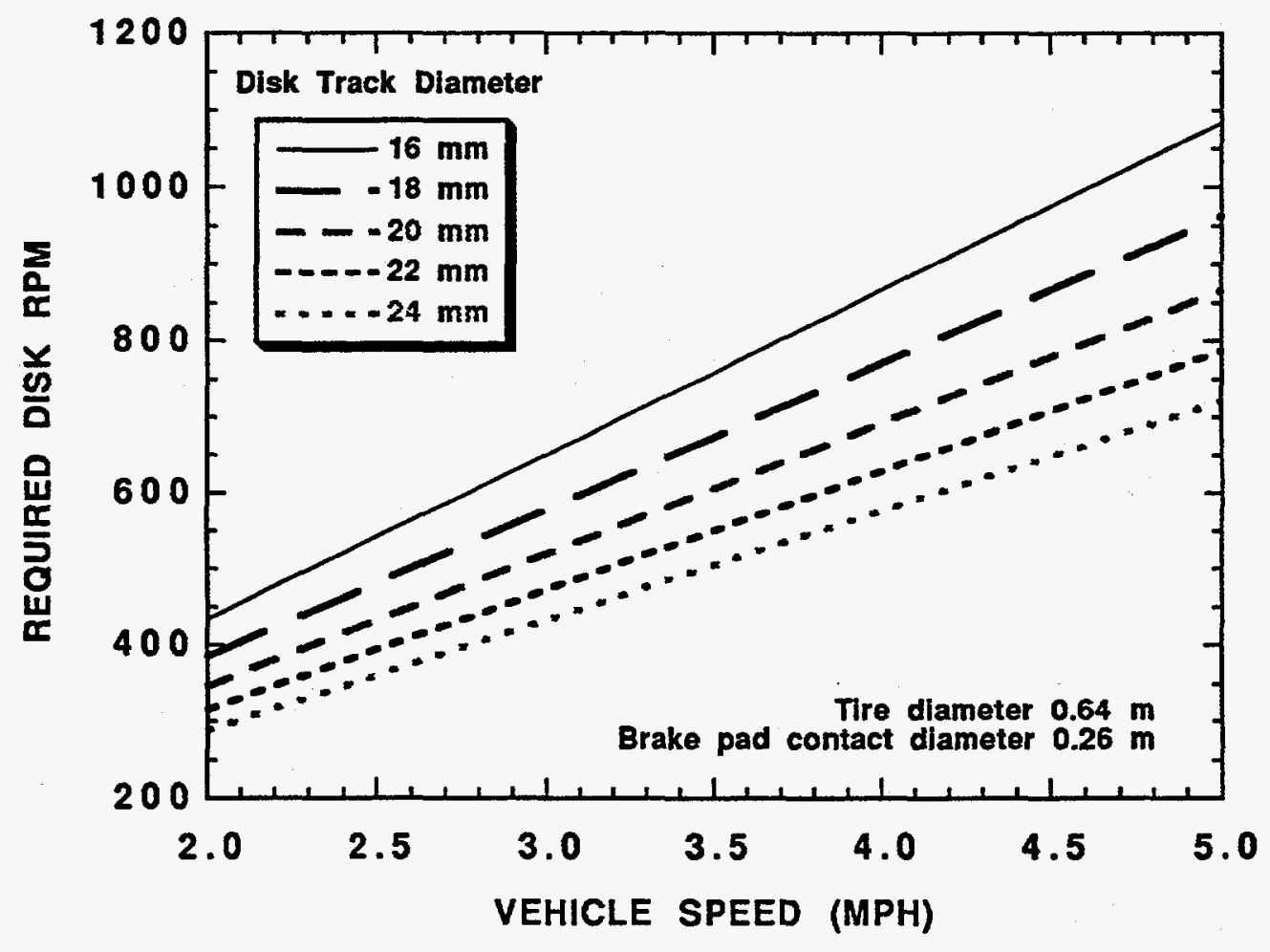

Figure 3. 
OD-1022

Type C, $2.97 \mathrm{~N}, 600 \mathrm{rpm}$

First $10 \mathrm{sec}$

$\mu$

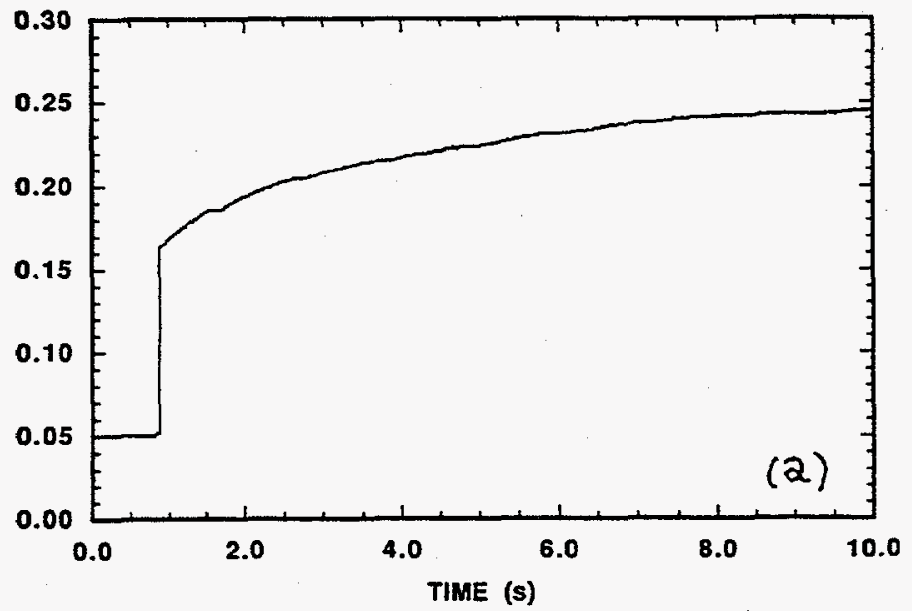

START-UP

Type C, $2.97 \mathrm{~N}, 600 \mathrm{rpm}$

Middle $10 \mathrm{sec}$

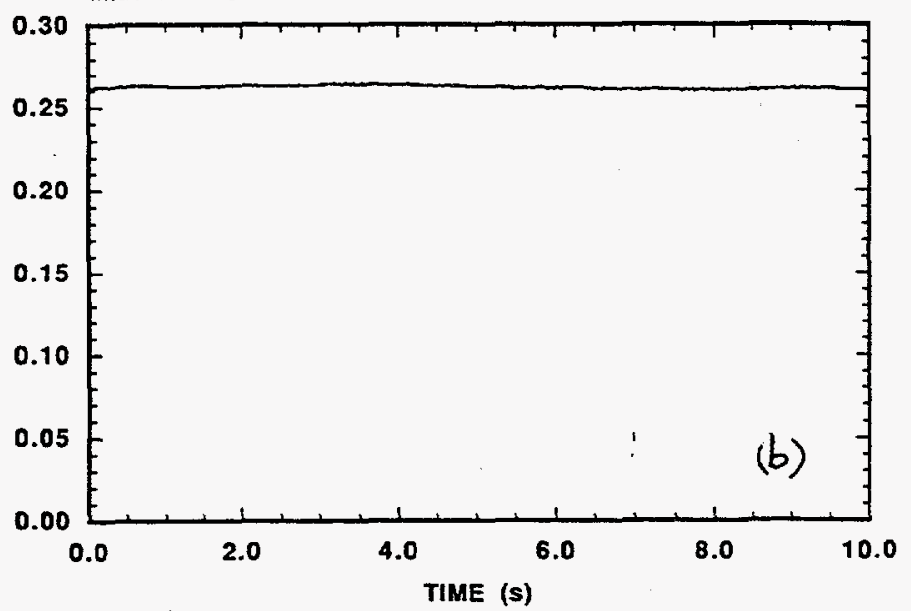

MID-TEST

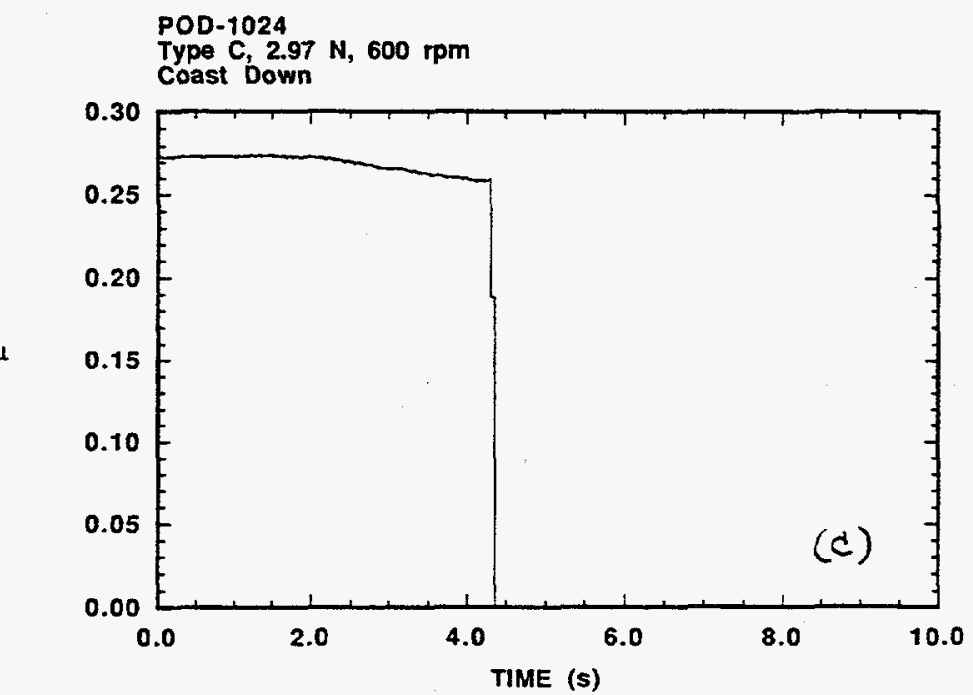

COAST-DOWN 

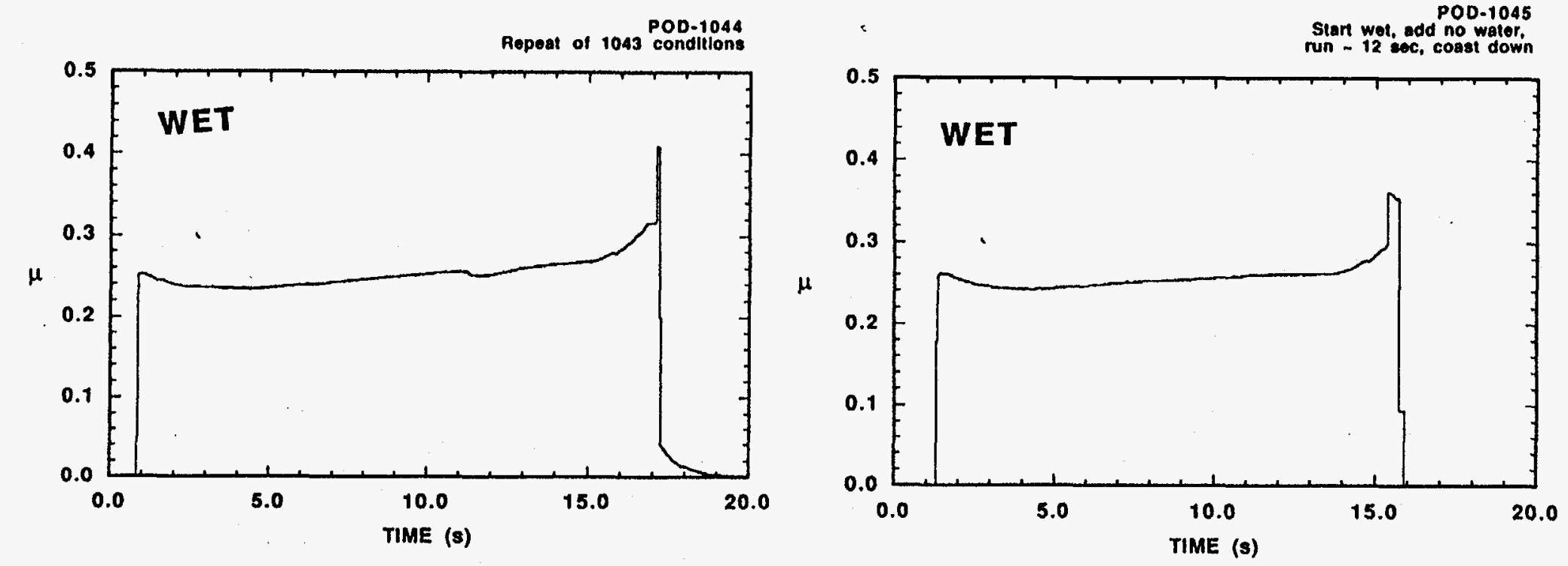

$ซ$
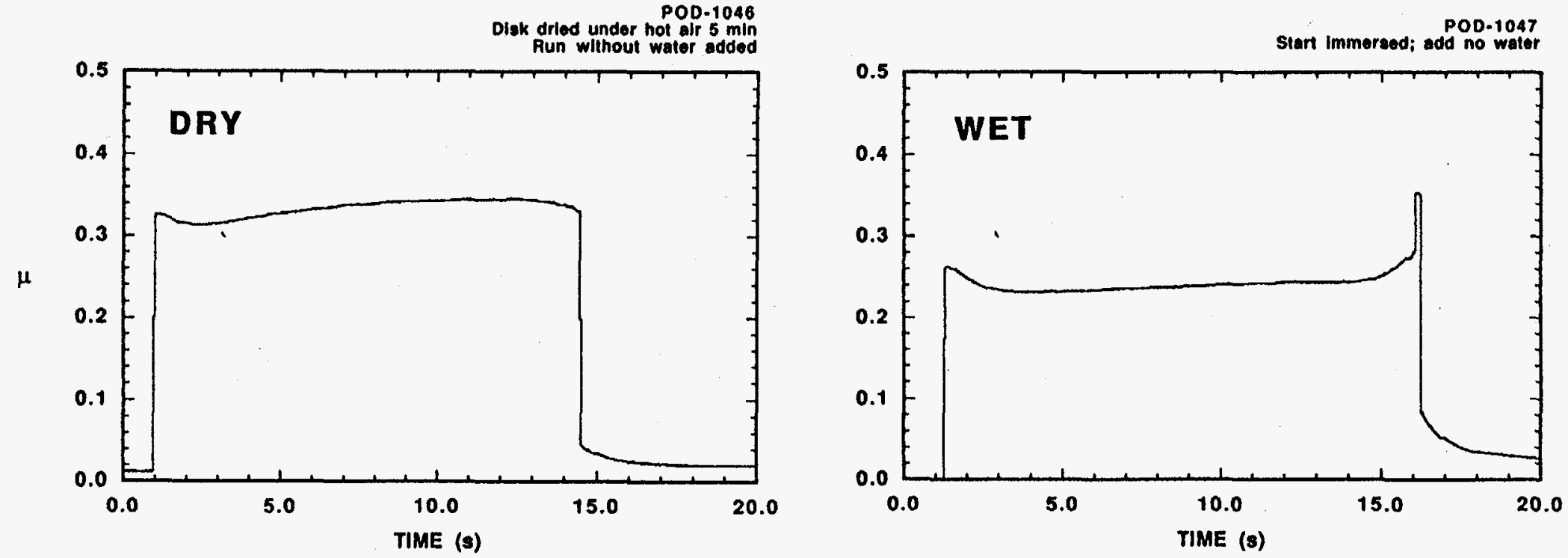

Figure 5. 


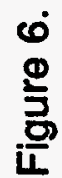

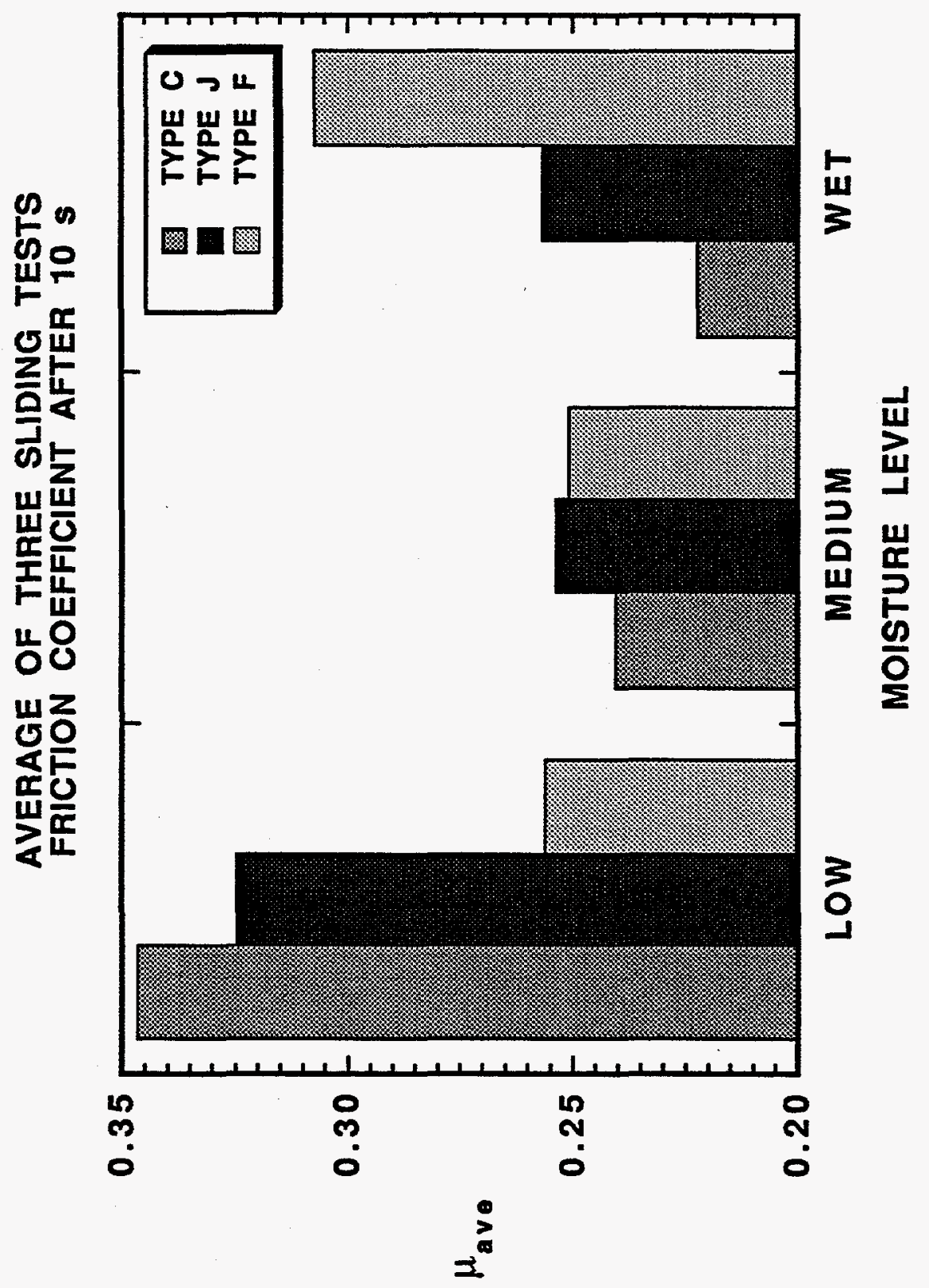




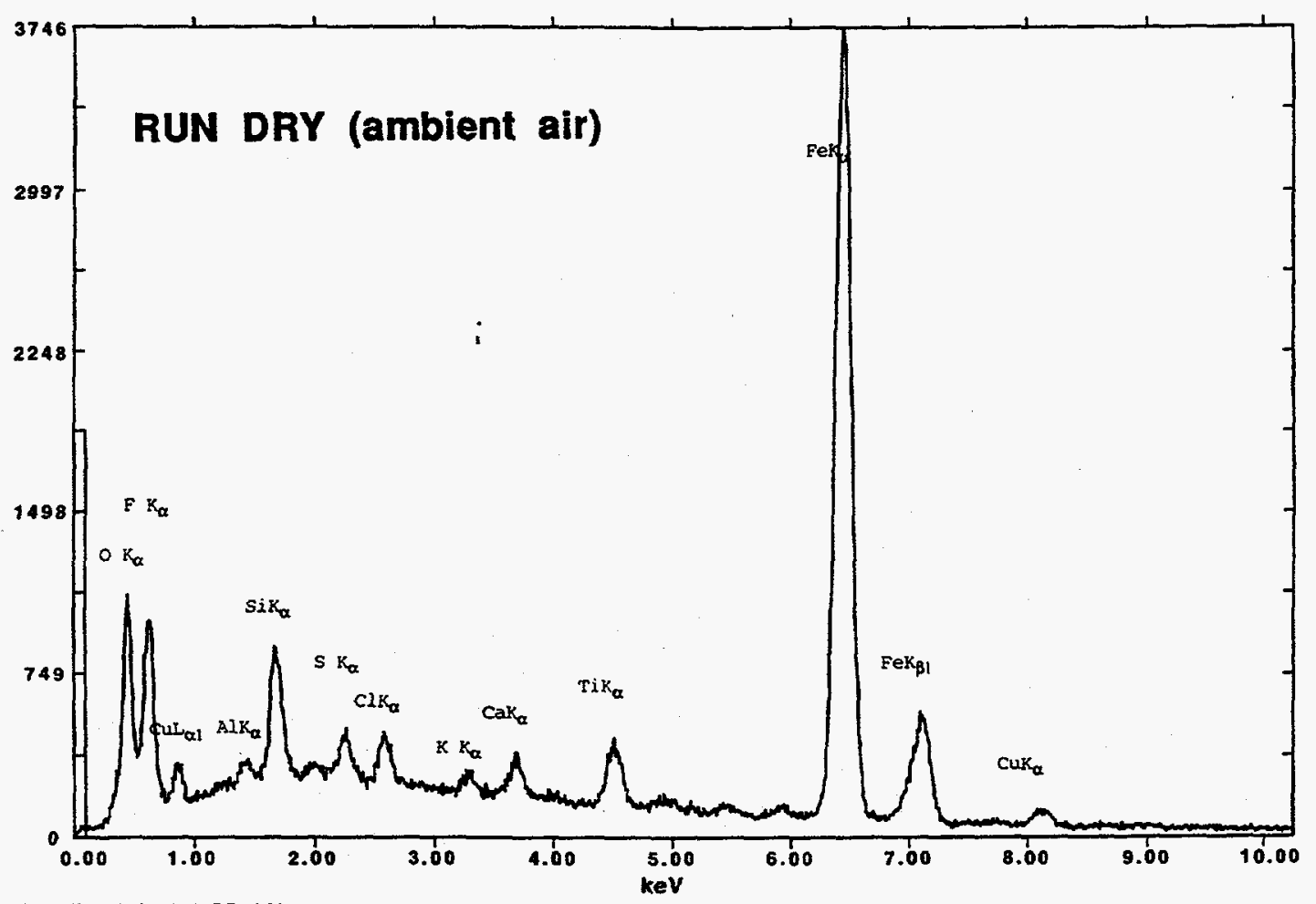

CAST FE PIN POD-1071

$4 \times 5$ MICRON AREA NEAR LEADNG EDGE

Analyst. P J BLAU keV: 20.00 Current; 0.00 Live Tume: 100.00 OV/Channel 10.00

Detector Resolution: $145.00 \mathrm{eV}$ Take-oft angle $=25.00$

Markers for Be, 4

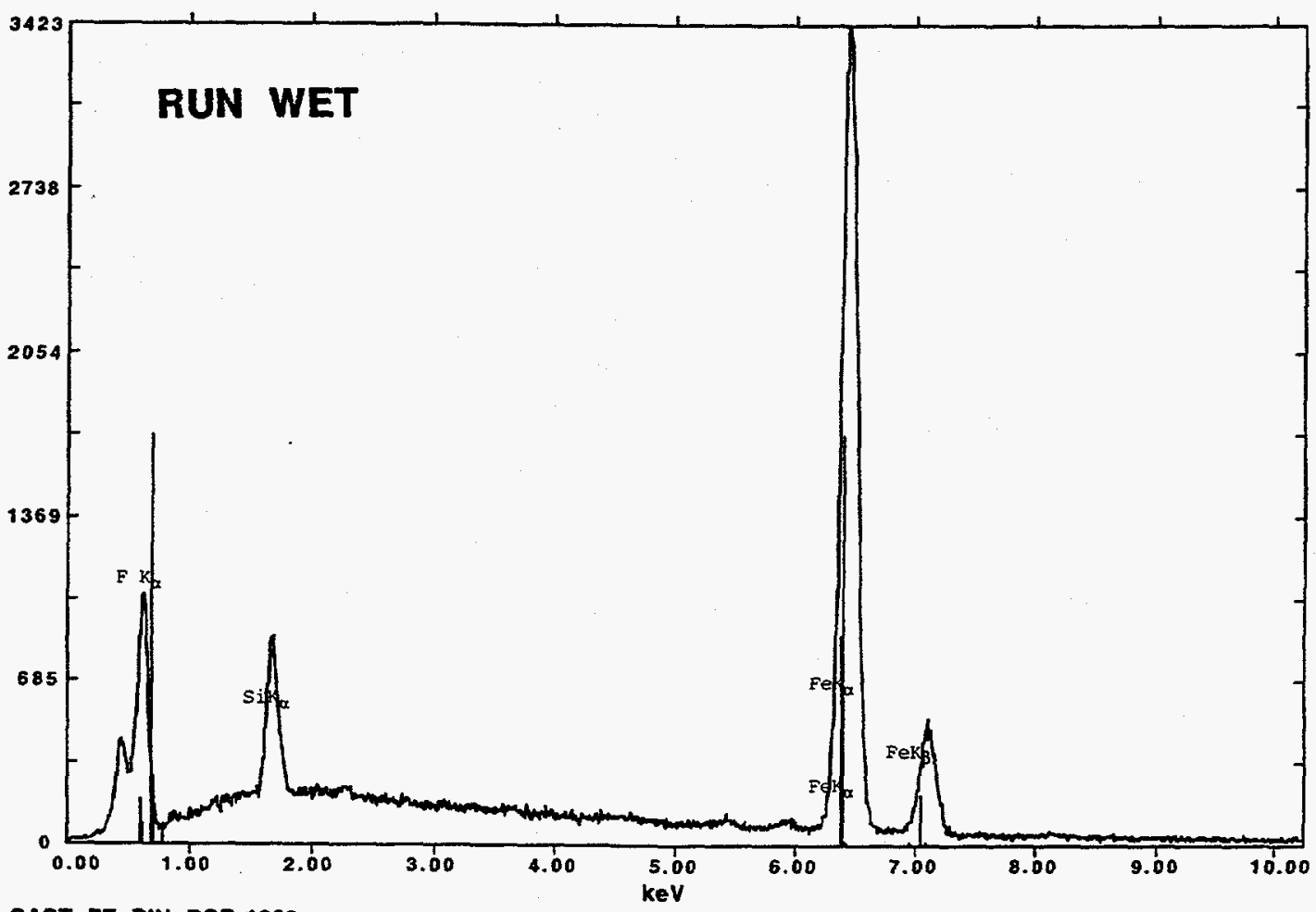

CAST FE PIN POD-1069

PIN FOR POD 1069 - ABOUT $100 \times 100$ MICRON AREA

Analyst: PJ BLAU keV: 20.00 Current 0.00 Live Time: 72.80 eV/Channet= 10.00

Detector flesolution: $145.00 \mathrm{eV}$ Take-oft angle $=\mathbf{2 5 . 0 0}$

Markers for Fe, 26 


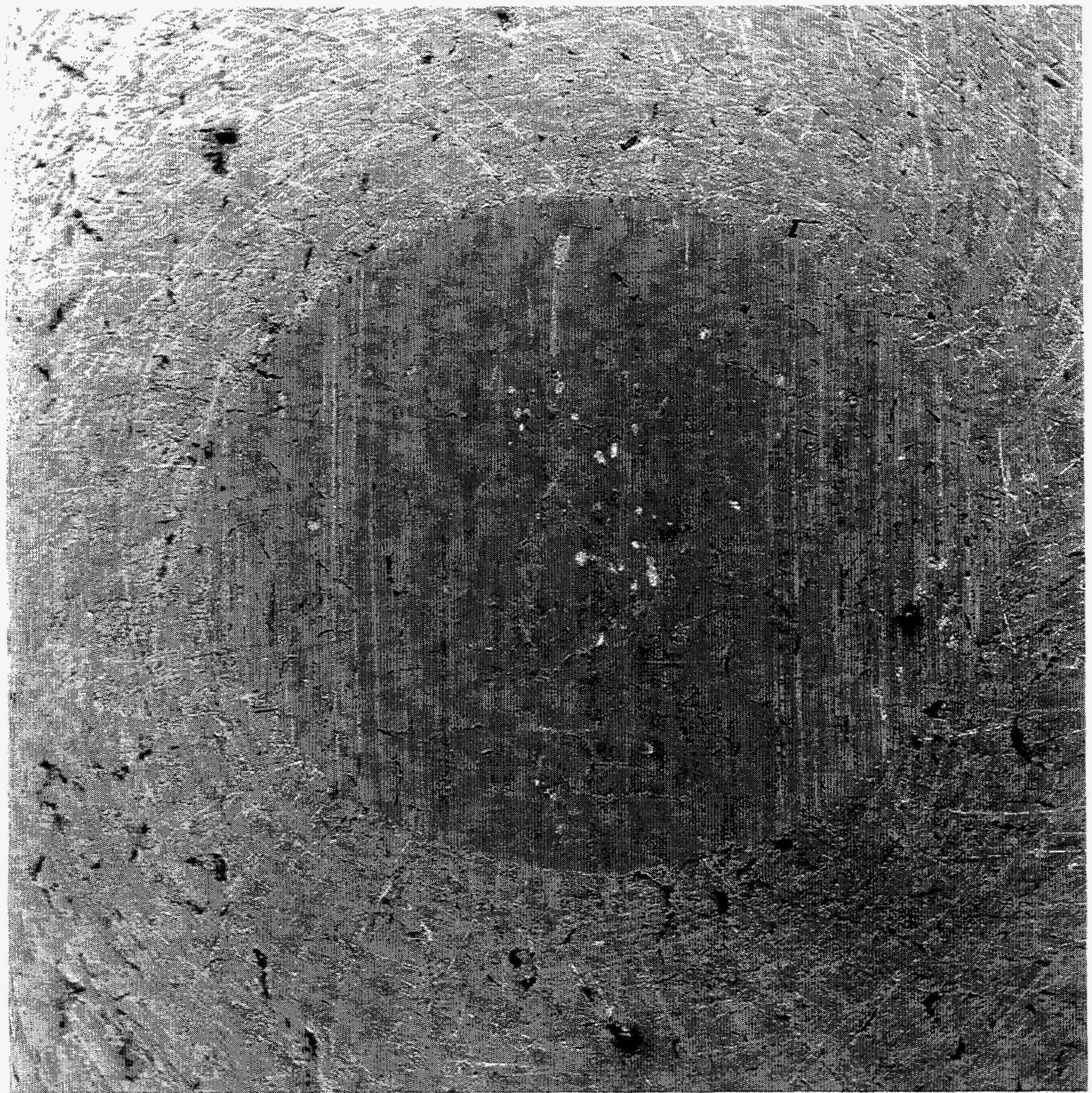

SCAR DIAMETER $=1.47 \mathrm{~mm}$

Figure 8. 
Appendix 1 - List of Experiments and Conditions

\begin{tabular}{|c|c|c|c|c|c|c|c|c|}
\hline POD \# & Pin & Disk & $\operatorname{Load}(\mathrm{N}$ & ss (psi) & $\% \mathrm{RH}$ & el (m/s) & Duration & Special Conditions \\
\hline 1004 & new & $\mathrm{J}$ & 2.97 & 396.2 & 69 & 0.833 & 10 & \\
\hline 1005 & used (1x) & $J$ & 2.97 & 390.4 & 69 & 0.958 & 10 & \\
\hline 1006 & used (2x) & $J$ & 2.97 & 389.0 & 69 & 0.613 & 10 & \\
\hline 1007 & used (3x) & $\mathrm{J}$ & 2.97 & 397.6 & 65 & 0.707 & 20 & \\
\hline 1008 & new & $J$ & 2.97 & & 65 & 0.738 & 5 & coast down \\
\hline 1009 & used (1x) & $\mathrm{J}$ & 2.97 & & 65 & 0.848 & 5 & coast down \\
\hline 1010 & used (2x) & $J$ & 2.97 & & 65 & 0.958 & 5 & coast down \\
\hline 1011 & used $(3 x)$ & $J$ & 2.97 & 317.7 & 61 & 0.597 & 10 & first $10 \mathrm{sec}$ \\
\hline 1011 & used $(3 x)$ & $\mathrm{J}$ & 2.97 & 317.7 & 61 & 0.597 & 310 & after $5 \mathrm{~min}$ \\
\hline 1011 & used (3x) & $J$ & 2.97 & 317.7 & 61 & 0.597 & 600 & last $10 \mathrm{sec}$ \\
\hline 1012 & new & $J$ & 2.97 & & 74 & & & \\
\hline 1013 & used (1X) & $\mathrm{J}$ & 2.97 & & 65 & & & - \\
\hline 1016 & new & $\mathrm{C}$ & 2.97 & 269.1 & 67 & 0.880 & 10 & first $10 \mathrm{sec}$ \\
\hline 1017 & new & c & 2.97 & 269.1 & 67 & 0.880 & 310 & after $5 \mathrm{~min}$ \\
\hline 1018 & new & $C$ & 2.97 & 269.1 & 67 & 0.880 & 600 & last $10 \mathrm{sec}$ \\
\hline 1019 & used(1x) & $C$ & 2.97 & 263.0 & 63 & 0.754 & 10 & first $10 \mathrm{sec}$ \\
\hline 1020 & used(1x) & $c$ & 2.97 & 263.0 & 63 & 0.754 & 310 & after $5 \mathrm{~min}$ \\
\hline 1021 & used(1x) & $C$ & 2.97 & 263.0 & 63 & 0.754 & 600 & last $10 \mathrm{sec}$ \\
\hline 1022 & used (2x) & $\mathrm{C}$ & 2.97 & 260.0 & 63 & 0.628 & 10 & first $10 \mathrm{sec}$ \\
\hline 1023 & used (2x) & $\mathrm{C}$ & 2.97 & 260.0 & 63 & 0.628 & 310 & after $5 \mathrm{~min}$ \\
\hline 1024 & used (2x) & $\mathrm{C}$ & 2.97 & 260.0 & 63 & 0.628 & 600 & last $10 \mathrm{sec}$ \\
\hline 1025 & new & $\mathbf{F}$ & 2.97 & 269.6 & 59 & 0.895 & 10 & first $10 \mathrm{sec}$ \\
\hline 1026 & new & $F$ & 2.97 & 269.6 & 59 & 0.895 & 310 & after $5 \mathrm{~min}$ \\
\hline 1027 & new & $F$ & 2.97 & 269.6 & 59 & 0.895 & 600 & last $10 \mathrm{sec}$ \\
\hline 1028 & used(1x) & $F$ & 2.97 & 267.6 & 59 & 0.785 & 10 & first 10 sec \\
\hline 1029 & used(1x) & $F$ & 2.97 & 267.6 & 59 & 0.785 & 310 & after $5 \mathrm{~min}$ \\
\hline 1030 & used(1x) & $\mathrm{F}$ & 2.97 & 267.6 & 59 & 0.785 & 600 & last 10 sec \\
\hline 1031 & used $(2 x)$ & $F$ & 2.97 & 265.6 & 59 & 0.660 & 10 & first 10 sec \\
\hline 1032 & used (2x) & $F$ & 2.97 & 265.6 & 59 & 0.660 & 310 & after $5 \mathrm{~min}$ \\
\hline 1033 & used (2x) & $F$ & 2.97 & 265.6 & 59 & 0.660 & 600 & last 10 sec \\
\hline 1034 & new & $\mathrm{J}$ & 2.97 & 276.3 & 59 & 1.005 & 10 & first $10 \mathrm{sec}$ \\
\hline 1035 & new & $\mathrm{J}$ & 2.97 & 276.3 & 59 & 1.005 & 310 & after $5 \mathrm{~min}$ \\
\hline 1036 & new & $\mathrm{J}$ & 2.97 & 276.3 & 59 & 1.005 & 600 & last $10 \mathrm{sec}$ \\
\hline 1037 & used(1x) & $\mathrm{J}$ & 2.97 & 280.5 & 59 & 0.848 & 10 & first $10 \mathrm{sec}$ \\
\hline 1038 & used(1x) & $J$ & 2.97 & 280.5 & 59 & 0.848 & 310 & after $5 \mathrm{~min}$ \\
\hline 1039 & used(1x) & $J$ & 2.97 & 280.5 & 59 & 0.848 & 600 & last $10 \mathrm{sec}$ \\
\hline 1040 & used (2x) & $\mathrm{J}$ & 2.97 & 272.9 & 59 & 0.424 & 10 & first $10 \mathrm{sec}$ \\
\hline 1041 & used (2x) & $\mathrm{J}$ & 2.97 & 272.9 & 59 & 0.424 & 310 & after $5 \mathrm{~min}$ \\
\hline 1042 & used (2x) & $\mathrm{J}$ & 2.97 & 272.9 & 59 & 0.424 & 600 & last $10 \mathrm{sec}$ \\
\hline 1043 & new & $\mathrm{J}$ & 2.97 & 275.4 & 58 & 0.581 & 12 & spec run wet \\
\hline 1044 & used(1x) & $\mathrm{J}$ & 2.97 & 275.4 & 58 & 0.660 & 12 & spec run wet \\
\hline 1045 & used(2x) & $J$ & 2.97 & 275.4 & 58 & 0.754 & 12 & start wet add no water \\
\hline
\end{tabular}




\begin{tabular}{|c|c|c|c|c|c|c|c|c|}
\hline 1046 & used (3x) & $J$ & 2.97 & 275.4 & 62 & 0.848 & 12 & dried undr drier \\
\hline 1047 & used (4x) & $J$ & 2.97 & 275.4 & 63 & 1.005 & 12. & spec run wet \\
\hline 1048 & new & $\mathrm{C}$ & 2.97 & 264.5 & 59 & 0.594 & 12 & spec run wet \\
\hline 1049 & used(1x) & $\mathrm{C}$ & 2.97 & 264.5 & 59 & 0.707 & 12 & spec run wet \\
\hline 1050 & used(2x) & $C$ & 2.97 & 264.5 & 59 & 0.804 & 12 & spoc run wet \\
\hline 1051 & new & $F$ & 2.97 & 149.6 & 59 & 0.534 & 12 & spec run wet \\
\hline 1052 & used(1x) & $F$ & 2.97 & 149.6 & 59 & 0.691 & 12 & spec run wet \\
\hline 1053 & used (2x) & $\mathrm{F}$ & 2.97 & 149.6 & 59 & 0.848 & 12 & spec run wet \\
\hline 1054 & new & $j$ & 0.99 & 143.4 & 60 & 0.565 & 10 & $\sim 1.5 \mathrm{sec} \times 5$ times \\
\hline 1055 & used(1x) & $J$ & 1.99 & 288.3 & 60 & 0.660 & 10 & $\sim 1.5 \mathrm{sec} \times 5$ times \\
\hline 1056 & used(2x) & $\mathrm{J}$ & 2.97 & 430.2 & 60 & 0.754 & 10 & $\sim 1.5$ sec $\times 5$ times \\
\hline 1057 & used (3x) & $\mathrm{J}$ & 3.97 & 575.1 & 60 & 0.817 & 10 & $-1.5 \mathrm{sec} \times 5$ times \\
\hline 1058 & new & $\mathrm{J}$ & 2.97 & 152.4 & $<1 \%$ & 0.534 & 12 & pump down/backfill $3 x$ \\
\hline 1059 & used (1x) & $\mathrm{J}$ & 2.97 & 152.4 & $<1 \%$ & 0.660 & 12 & pump down/backfill $3 x$ \\
\hline 1060 & used (2x) & $\mathrm{J}$ & 2.97 & 152.4 & $<1 \%$ & 0.848 & 12 & pump down/backfill $3 x$ \\
\hline 1061 & new & $\mathrm{F}$ & 2.97 & 224.3 & $<1 \%$ & 0.565 & 12 & pump down/backfill $3 x$ \\
\hline 1062 & used (1x) & $F$ & 2.97 & 224.3 & $<1 \%$ & 0.628 & 12 & pump down/backfill $3 x$ \\
\hline 1063 & used (2x) & $F$ & 2.97 & 224.3 & $<1 \%$ & 0.785 & 12 & pump down/backfill $3 x$ \\
\hline 1064 & new & $\mathrm{C}$ & 2.97 & 226.9 & $<1 \%$ & 0.660 & 12 & pump down/backfill $3 x$ \\
\hline 1065 & used (1x) & $\mathrm{C}$ & 2.97 & 226.9 & $<1 \%$ & 0.785 & 12 & pump down/backfill $3 x$ \\
\hline 1066 & used (2x) & $\mathrm{C}$ & 2.97 & 226.9 & $<1 \%$ & 0.880 & 12 & pump down/backfill $3 x$ \\
\hline 1067 & new & $J$ & 2.97 & 248.9 & 44 & 0.880 & 10 & start wet, $\sim 1.5 \sec \times 5$ times \\
\hline 1068 & used (1x) & $J$ & 2.97 & 248.9 & 44 & 1.068 & 10 & wet start, $\sim 1.5 \sec \times 5$ times \\
\hline 1069 & used (2x) & $\mathbf{J}$ & 2.97 & 248.9 & 44 & 0.628 & 10 & add water, $\sim 10$ sec drag \\
\hline 1070 & new & 220 grit & 2.97 & & 44 & 0.628 & 3 & air \\
\hline 1071 & new & $\mathbf{J}$ & 2.97 & & 44 & 0.691 & 30 & $-10 \mathrm{sec}+20 \mathrm{sec}$ \\
\hline 1072 & new & c & 2.97 & 207.9 & 46 & 0.707 & 10 & wet start, $\sim 1.5 \mathrm{sec} \times 5$ times \\
\hline 1073 & used (1x) & C & 2.97 & 207.9 & 46 & 0.848 & 10 & wet start, $-1.5 \sec \times 5$ times \\
\hline 1074 & new & $F$ & 2.97 & 187.5 & 46 & 0.817 & 10 & wet start, $\sim 1.5 \sec \times 5$ times \\
\hline 1075 & used (1x) & $\mathrm{F}$ & 2.97 & 187.5 & 46 & 0.911 & 10 & wet start, $\sim 1.5 \mathrm{sec} \times 5$ times \\
\hline
\end{tabular}




\section{Appendix 2}

\section{Summary of Rotor and Disc Brake Pad Material Analysis}

\subsection{Introduction}

This Appendix summarizes the characterization work completed in accordance with Task 1 of CRADA ORNL 94-0286 between Martin Marietta Energy Systems, Inc., Oak Ridge National Laboratory, and Ford Motor Company. Both new and previously-tested brake pads and rotors were supplied by Ford for examination. Ford also supplied electron micrographs and chemical analysis data for the same materials. Initial characterization included surface roughness measurements on rotors, metallographic polishing and microindentation hardness tests on cast iron rotors, optical microscopy and examination of pads and rotors, scratch and microindentation hardness tests of pad materials, and extraction of particles from worn pad surfaces by an adhesive peel-off extraction technique. Results provided herein should be considered preliminary since the amount of material used was limited and may not represent the general population of pad and rotor materials.

\subsection{Materials}

Ford provided unused pad materials used for automotive front disc brakes. They also provided specimens of special pads in which both the abrasive and lubricating additives had been doubled over the standard composition. There were at least 15 constituents in the pad materials. The basic material is designated herein as "OO" and the high abrasive - high lubricant material is designated "J." Sectioned rotors which had been tested against the pad materials were also supplied.

\subsection{Rotor Microstructure and Microindentation Hardness}

A polished section of one of the cast iron rotors was metallographically-prepared. A photomicrograph of the unetched section is shown in Fig. A2.1. It exhibits the typical appearance of gray cast iron with its flakes of graphite. At higher magnifications, small inclusions suggestive of sulfides and small, pink-colored angular phosphides were observed. Microindentation hardness tests of the polished rotor material were performed to assess its hardness as a function of indenter load. Knoop indentations were made in graphite flake-free areas at loads of 15, 25, 50 and $100 \mathrm{gf}$ $(14.7,24.5,49.1$, and $98.1 \mathrm{mN})$. The microindentation hardness number was essentially independent of load and averaged about $3.1 \pm 0.5 \mathrm{GPa}$.

\subsection{Worn Rotor Surfaces}

Cast iron brake rotors dynamometer-tested against type " 00 " and "J" pads were provided by Ford SRL. After EDM slicing, surface roughness measurements were made using a Rank Taylor-Hobson Talysurf ${ }^{\mathrm{TM}} 10$ profiling instrument on opposite sides of both rotors. In order to determine whether one or another of the standard measures of surface texture would be more sensitive to wear-induced differences in the rotors, several parameters were measured: arithmetic roughness $\left(R_{a}\right)$, root-mean-square roughness $\left(R_{q}\right)$, peak-to-valley roughness $\left(R_{t}\right)$, kurtosis $\left(R_{k u}\right)$, skew $\left(\mathbf{R}_{\text {Sk }}\right)$, and mean deviation of asperity slope from the average asperity slope (delQ). Six measurements of each parameter were made on the inner and outer rotor surfaces. A cut-off length of $0.8 \mathrm{~mm}$ with 7 cut-off's was used with a $2 \mu \mathrm{m}$ stylus tip and an ISO data filter. 
Roughness data are given in Table A2.1 (a)-(d). They should be considered at best preliminary since the number of samples studied was quite small. "Side 1 " was the rotor side which normally faces to the outside of the vehicle. There were small differences in the roughness values measured on opposite faces of the rotor. Since areas too far inboard to be subjected to rubbing possessed essentially the same $R_{a}$ and $R_{q}$ as the areas which were in contact with the pads, most of the roughness could be attributed to the original turning process and relatively little to the wear process. Thus, wear measurements using profiling methods may need to consider some of the more subtle differences in roughness parameters for worn and unworn rotors such as AbbottFirestone bearing area curves or the amplitude distribution function.

The peak-to-valley height was slightly higher in the worn area than the unworn area on one of the surfaces (as shown in Fig. A2.2 (a) - (d)). With asperities on the original surface being worn down, one would expect the peak-to-valley roughness to decrease, not to increase as the data show. Thus, it is not clear that this trend resulted from wear but rather may have been due to variations due to turning and finishing. There was also an increase in delQ in the worn area. Higher asperity slopes would be consistent with larger peak-to-valley roughness given a constant distance between peaks, a trend which would be observed if the tool feed during the rotor tuming operation were kept constant but the depth of cut varied due to tool tip wear or set-up errors.

Examination of Ford Photomicrographs of Rotors. A collection of scanning electron micrographs of worn rotors were provided for study by Bill Donlon, Ford SRL. These were contained within a Ford report and will not be reproduced here. Images clearly indicated the nonuniformity of wear features on the rotors, particularly with regard to the distribution of patches of transferred material. Transfer patches tended to consist of assemblages of compacted fine particles. These regions displayed edges which suggested that they fracture by crack propagation along the particle interfaces, but the possibility of trans-particle fracture during transfer film removal cannot be excluded. In fact, several photomicrographs depicted areas in which the highly-compressed surface layers were in the process of delaminating rather than fracturing along more granular boundaries. Adhesive pull-out of transfer layers may also occur on occasion.

There was also clear evidence that transferred pad material can collect in local depressions in the rotor surfaces. These depressions may be produced either by wear or by external surface damage to the rotors ("dings" or "gouges"). Other transfer patches appeared to be clinging to the "up-stream" side of transverse gouges in the surface, suggesting that a slight upset near the gouge edge may serve to collect (by scuffing or shaving) transferred material preferentially.

Metallic portions of the worn rotor exhibit clear indications of plastic flow in shear. In some cases these flowed features are manifest by waviness in the graphite flakes exposed at the surface. In other cases, there are flat, finger-like features lying in the sliding direction suggesting that material may be drawn out into thin pointed strips, and torn off at the end. The presence of long, continuous striations are suggestive of abrasion by small hard particles.

Like the worn pads, rotor surfaces are suggestive that several wear modes are occurring simultaneously: abrasive wear, surface fatigue, and plastic deformation followed by tearing. The ductile nature of the cast iron, however, did not permit the degree of brittle material removal that was exhibited by the pad material. Transfer films may alter surface tractions locally, thereby protecting the underlying rotor surface from wear damage, if only momentarily.

\subsection{Microindentation Studies of Sectioned Brake Pads}

A series of metallographically-polished cross-sections were prepared of materials type "OO" and "J." Their complex microstructures are revealed in Fig. A2.3. Knoop microindentation hardness tests were performed on the "OO" material on particles within the microstructure that 
ROUGHNESS DATA FOR DYNAMOMETER-TESTED ROTORS

\begin{tabular}{|c|c|c|c|c|c|c|}
\hline \multicolumn{7}{|c|}{ Rotor F4H-205-3 (pad type "J") } \\
\hline \multicolumn{7}{|c|}{ Side 1 (facing to the outside of the rotor) } \\
\hline & & & & & & \\
\hline Distance from & $\mathbf{R a}$ & $\mathbf{R q}$ & Rt & Kurtosis & Skew & DelQ \\
\hline Inner edge (mm) & $(\mu \mathrm{m})$ & $(\mu \mathrm{m})$ & $(\mu \mathrm{m})$ & & & (degrees) \\
\hline & & & & & & \\
\hline 11.4 & 0.77 & 1.03 & 9.0 & 8.01 & -1.15 & 5.72 \\
\hline 17.0 & 0.62 & 0.78 & 5.9 & 3.43 & -0.22 & 4.26 \\
\hline 22.6 & 0.75 & 1.00 & 7.9 & 5.31 & -0.68 & 5.57 \\
\hline 28.2 & 1.02 & 1.34 & 9.0 & 4.09 & -0.58 & 7.32 \\
\hline 33.8 & 0.91 & 1.18 & 9.2 & 3.70 & -0.18 & 6.19 \\
\hline 39.4 & 0.88 & 1.14 & 8.6 & 5.16 & -0.84 & 5.53 \\
\hline 45.0 & 0.88 & 1.30 & 12.8 & 11.95 & $|-1.60|$ & 6.15 \\
\hline & & & & & & \\
\hline Average $=$ & 0.83 & 1.11 & 8.91 & 5.95 & -0.75 & 5.82 \\
\hline Std. Dev. $=$ & 0.13 & 0.19 & 2.06 & 3.06 & 0.51 & 0.92 \\
\hline
\end{tabular}

(a)

\begin{tabular}{|c|c|c|c|c|c|c|}
\hline \multicolumn{7}{|c|}{ Side 2 (opposite side) } \\
\hline Distance from & $\mathbf{R a}$ & $\mathbf{R q}$ & Rt & Kurtosis & Skew & DelQ \\
\hline inner edge (mm) & $(\mu \mathrm{m})$ & $(\mu \mathrm{m})$ & $(\mu \mathrm{m})$ & & & (degrees) \\
\hline 18.8 & 0.85 & 1.10 & 9.6 & 5.11 & -0.46 & 5.32 \\
\hline 24.4 & 0.93 & 1.21 & 10.4 & 5.39 & -0.22 & 4.95 \\
\hline 30.0 & 0.87 & 1.06 & 6.2 & 2.89 & -0.35 & 5.24 \\
\hline 35.6 & 0.80 & 0.97 & 6.1 & 2.97 & -0.44 & 4.98 \\
\hline 41.2 & 0.92 & 1.14 & 6.9 & 3.37 & -0.60 & 6.38 \\
\hline 46.8 & 1.24 & 1.58 & 11.8 & 3.65 & -0.36 & 8.61 \\
\hline Average $=$ & 0.94 & 1.18 & 8.50 & 3.90 & -0.41 & 5.91 \\
\hline Std. Dev. $=$ & 0.16 & 0.21 & 2.42 & 1.09 & 0.13 & 1.42 \\
\hline
\end{tabular}

(b) 


\begin{tabular}{|c|c|c|c|c|c|c|}
\hline \multicolumn{7}{|c|}{ Rotor 4L32-S-1 (pad type "00") } \\
\hline & & & & & & \\
\hline \multicolumn{7}{|c|}{ Side 1 (facing to the outside of the rotor) } \\
\hline & & & & & & \\
\hline Distance from & $\mathbf{R a}$ & $\mathbf{R q}$ & $\mathbf{R t}$ & Kurtosis & Skew & DelQ \\
\hline inner edge (mm) & $(\mu \mathrm{m})$ & $(\mu \mathrm{m})$ & $(\mu \mathrm{m})$ & & & (degrees) \\
\hline & & & & & & \\
\hline 12.4 & 0.64 & 0.79 & 5.1 & 3.20 & -0.41 & 3.95 \\
\hline 18.0 & 0.83 & 0.99 & 7.1 & 2.71 & -0.20 & 4.14 \\
\hline 23.6 & 0.73 & 0.94 & 6.2 & 3.61 & -0.36 & 4.03 \\
\hline 29.2 & 0.94 & 1.10 & 5.1 & 2.00 & -0.03 & 3.48 \\
\hline 34.8 & 0.66 & 0.81 & 5.3 & 2.83 & -0.04 & 3.10 \\
\hline 40.4 & 0.90 & 1.13 & 7.6 & 3.61 & -0.34 & 4.02 \\
\hline & & & & & & \\
\hline Average $=$ & 0.78 & 0.96 & 6.07 & 2.99 & -0.23 & 3.79 \\
\hline Std. Dev. $=$ & 0.13 & 0.14 & 1.09 & 0.62 & 0.17 & 0.41 \\
\hline
\end{tabular}

(c)

\begin{tabular}{|c|c|c|c|c|c|c|}
\hline \multicolumn{2}{|c|}{ Side 2 (opposite side) } & & & & & \\
\hline Distance from & $\mathbf{R a}$ & $\mathbf{R q}$ & $\mathbf{R t}$ & Kurtosis & Skew & DelQ \\
\hline inner edge (mm) & $(\mu \mathrm{m})$ & $(\mu \mathrm{m})$ & $(\mu \mathrm{m})$ & & & (degrees) \\
\hline & & & & & & \\
\hline 6.8 & 0.80 & 1.03 & 10.0 & 6.13 & -0.46 & 4.23 \\
\hline 12.4 & 0.85 & 1.08 & 8.6 & 5.61 & -0.99 & 4.16 \\
\hline 18.0 & 0.66 & 0.79 & 5.0 & 2.50 & -0.13 & 3.60 \\
\hline 23.6 & 0.80 & 1.05 & 8.8 & 5.77 & -0.71 & 4.04 \\
\hline 29.2 & 0.63 & 0.79 & 5.2 & 3.27 & -0.31 & 3.72 \\
\hline 34.8 & 1.28 & 1.82 & 15.4 & 9.14 & -1.49 & 6.23 \\
\hline 40.4 & 0.77 & 1.16 & 11.7 & 15.43 & -2.06 & 4.15 \\
\hline 46.0 & 0.88 & 1.19 & 10.3 & 6.28 & -0.57 & 4.63 \\
\hline Average $=$ & 0.83 & 1.11 & 938 & $6 \pi$ & -0.84 & 435 \\
\hline Std. Dev. $=$ & 0.20 & 0.32 & 3.39 & 4.04 & 0.65 & 0.82 \\
\hline
\end{tabular}

(d) 
appeared to be smooth and large enough to accommodate the impression made with a 15 gf load. Without a list of ingredients, it was not possible to identify the species being indented, but only to describe them by general shape, color, and appearance. Approximately one in three indentations produced a measurable impression. In other cases, the particle fractured or deformed so severely that the hardness reading was not possible. Table A2.2 lists microindentation hardness numbers of a number of particles on which readable impression sizes were obtained. The average and standard deviations of the data are not reported since they would have little or no physical significance. Particles ranged in hardness between 0.15 and $10.10 \mathrm{GPa}$. For comparison, the average microindentation hardness of the rotor material tested under the same conditions was 3.1 $\mathrm{GPa}$, considerably softer than some of the harder constituents in the pad material, yet harder than others.

Table A2.2

\section{MICROINDENTATION HARDNESS OF BRAKE PAD CONSTITUENTS}

\begin{tabular}{|l|r|}
\hline \multicolumn{1}{|c|}{ Description } & HK (GPa) \\
\hline & \\
\hline medium gray mottled fragment & 0.15 \\
\hline two-phase fragment with light veins in dark matrix & 0.19 \\
\hline wide winding band of dark gray material & 0.20 \\
\hline light gray phase in a two phase particle & 0.26 \\
\hline large medium gray area & 0.31 \\
\hline light gray phase in a two phase particle & 0.39 \\
\hline dark area of a two phase particle & 0.46 \\
\hline golden colored particle & 1.23 \\
\hline large yellowish fragment resembling a cutting chip & 1.57 \\
\hline conglomerate of rounded grayish particles & 1.66 \\
\hline large yellowish fragment resembling a cutting chip & 1.77 \\
\hline large yellowish fragment resembling a cutting chip & 1.77 \\
\hline light gray textured fragment & 1.87 \\
\hline large yellowish fragment resembling a cutting chip & 1.91 \\
\hline conglomerate of rounded grayish particles & 3.38 \\
\hline light gray smooth chip & 3.46 \\
\hline light gray smooth chip & 4.03 \\
\hline light gray smooth chip & 4.33 \\
\hline light gray smooth chip & 4.41 \\
\hline round gray featureless bead & 9.18 \\
\hline round gray featureless bead & 10.10 \\
\hline
\end{tabular}

[ Note: GPa $\times 101.9=\mathrm{kg} / \mathrm{mm}^{2}$ ] 


\subsection{Wear Processes in Disc Brake Pads}

ORNL Examination. The surfaces of both worn and unworn disc brake pads of two types, standard and with increased lubricant and abrasive, were examined at ORNL at magnifications from 10 to $400 \mathrm{X}$, under various forms of light optical illumination (monochromatic, polarized, interference-contrast), to determine the types of processes by which particles become detached during sliding contact with the brake rotor. Image analysis of low-magnification images (15X) indicated about $13 \%$ porosity.

Since the pad material consists of a combination of hard, soft, ductile, and brittle constituents of various shapes and orientations, it was expected that the wear surface, and hence the wear particles produced would exhibit a wide range of wear features. This was indeed the case. Table A2.3 summarizes the types of wear and material removal processes indicated by light optical examination.

Table A2.3

Wear Processes in Brake Pads

\begin{tabular}{|l|l|}
\hline \multicolumn{1}{|c|}{ Type of Wear } & Constituent Exhibiting this Wear Type \\
\hline mild abrasive wear & $\begin{array}{l}\text { hard glassy particles, small irregular mineral } \\
\text { chips, and larger mineral plates }\end{array}$ \\
\hline cutting (moderate abrasive) wear & $\begin{array}{l}\text { larger mineral fragments and some matrix } \\
\text { material }\end{array}$ \\
\hline plowing wear & larger areas of resin matrix \\
\hline whole particle pull-out & $\begin{array}{l}\text { some mineral fragments and other constituents } \\
\text { who removal prevented their exact identification }\end{array}$ \\
\hline fracture and pull-out & brittle constituents of irregular shape \\
\hline cleavage and delamination & $\begin{array}{l}\text { peeling of mineral layers followed by pull-out } \\
\text { or fracture }\end{array}$ \\
\hline metallic wear with transfer & $\begin{array}{l}\text { shear of ductile materials (coppery-appearing } \\
\text { constituents) and loss by forward and back } \\
\text { transfer to the counterface surface }\end{array}$ \\
\hline
\end{tabular}


Of those listed above, pull-out, transfer, and fracture seem to be the three dominant wear processes. Pull-out of whole particles probably results from the fact that many of the constituents are only mechanically-held by the resin matrix material and not in any way chemically bonded to it. Those particles exposed at the surface in which the major diameter is at the surface would be the first to leave due to sliding contact. Particles whose major diameters are below the surface of the pad are held more tightly. Thus, they would need to fracture or the surface would have to wear down in order for them to become a part of the debris. Metallic constituents and other low-shear strength species in the pads can smear across the surface of adjacent constituents and help to lubricate them while at the same time serving as a weak "glue" to retain them on the surface longer than would otherwise occur under sliding action. The brittle nature of some of the constituents became apparent during microindentation and scratch tests performed on polished sections of the pad material, described elsewhere in this report.

Once particles became detached from their original locations on the contact surface, there are several places they can go:

1. They can become trapped in surface voids in the pad left by lost particles or porosity.

2. They can deform and become part of a complex, mechanically-mixed transfer layer either on the pad or rotor contact surface.

3. They can become re-embedded in the rotor face much as an abrasive grain protrudes from a grinding wheel.

4. They can fall free from the contact area completely.

It is convenient to categorize the wear particles as being either active, in which they cause additional wear due to abrasive action, or passive in which they do not harm the wear surfaces. Passive wear particles include deposits of lubricious phases. The hardness of the pad constituents relative to the rotor material suggests that both active and passive third bodies are likely to be present in region of the contact surface in the present case.

Ford Photomicrographs. A collection of photomicrographs of unworn pad materials, obtained by scanning electron microscopy (taken in the secondary electron and backscattered imaging modes) was provided by Bill Donlon, Ford SRL. Like the optical images, SEM revealed the complex microstructure of the pad materials. Constituents included irregularly shaped particles, rounded particles, wire, fibrous matter, glassy-particles, and fragmented constituents. There was also a small amount of porosity. In addition, chemical analyses of certain indicated constituents was provided. These helped complete the picture of the original pad material and supplemented observations of worn surfaces described above.

\subsection{Extractions of Brake Pad Surface Material}

In order to study the loosely-adhered material clinging to the surface of the dynamometertested pad materials, several of the worn pads of Type "O" and " $\mathrm{J}$ " were subjected to adhesive debris extractions. Strongly-adhesive duct-type tape was applied to the surfaces of the worn pads and peeled off to extract debris particles. The extractions were taped to a glass slide and photographed at approximately $15 X$. The photographs were then analyzed with an image analysis system to determine the percent area of the tape occupied by adhesively-removed material. 
A photomicrograph of such an extraction is shown in Fig. A2.4. Note that there is a wide distribution of particle sizes and shapes. There was no evidence for the delamination of sheets or thin films from the pads, but rather the extractions all seemed to consist of discrete particles. The larger particles seemed to consist of shiny micaeous platelets. That observation is consistent with the tendency of mica to cleave easily along the plane of the sheets. The nature of the other fragments must await further analysis.

Table A2.4 gives the area percentages of the tape surface that were occupied by extracted particles. This percentage is a combination of the wear-produced particles and particles extracted from the surface just due to their low adhesive strength. The contribution of debris particles resulting from wear alone is therefore smaller than the reported total area percents of particles on the extraction tape surface. The uncertainty of the area \% data is likely to be at least $\pm 10 \%$ due to subjectivity in selecting the image analyzer detection threshold settings. Thus, the variation in the initial data suggest that it is not likely that extractions will produce significantly quantitative evidence for differences in the surface of the various pad types; however, the technique may provide a means to remove and examine the most-likely constituents to be lost by wear of the pad materials.

Table A2.4.

Surface Particle Extraction Data

\begin{tabular}{|c|c|c|}
\hline Pad Type & Specimen \# & Area \% Particles \\
\hline \hline $\mathrm{O}$ & $1 \mathrm{a}$ & 24.4 \\
\hline $\mathrm{J}$ & $1 \mathrm{~b}$ & 43.2 \\
\hline & $2 \mathrm{a}$ & 30.9 \\
\hline
\end{tabular}

\subsection{Scratch Tests of Polished Rotor and Brake Pad Materials}

Scratch tests were performed to assess the response of the rotor and pad materials to abrasion with a single point diamond and to measure the variation of the drag force on the abrading point as a measure of the contribution of various constituents in the rotor and pad to the friction along the surface. Therefore, polished specimens of a cast iron rotor and pad material type "OO" were prepared and subjected to a series of scratch tests using a Revetest ${ }^{\mathrm{TM}}$ (CSEM, Neuchatel, Switzerland) scratch testing machine. The indenter was a Rockwell hardness brale-type diamond indenter with a tip radius of $200 \mu \mathrm{m}$. A normal force of $200 \mathrm{~g}(1.96 \mathrm{~N})$ was used at slow sliding speed. The tangential (scratching) force was monitored with a load cell affixed to the specimen stage of the testing machine. A series of three scratches was performed, and the tangential force was recorded using a chart recorder. The chart recorder traces (e.g., Fig. A2.5 (a)) were digitized on a magnetic tablet (see Fig. A2.5 (b)) and the friction force data were entered into a spread sheet for analysis. The irregular shape of the trace is suggestive of the large variation in the resistance to abrasion from place-to-place on the pad surface. In all, 143 values of scratching force were measured on the rotor and 182 values were measured on the pad.

The frequency distributions of tangential force data are shown in Fig's. A2.6 (a) and (b). The average and standard deviation of the scratching forces for each material are given in Table A2.5. Interestingly, the average scratching force for the pad is about twice that for the rotor and the standard deviation is about ten times higher. This suggests that a hard particle abrading the surface of the pad would result in a much greater variation in sliding resistance than the same hard particle moving along the surface of the rotor material. 
In the pad material data, very low values of scratching force are probably due to momentary loss of traction when particles either fracture under the indenter tip or the indenter encounters a particle of soft, lubricious material. The highest values may be a result of the indenter becoming momentarily lodged in a large pore or pull-out cavity on the surface. The ratio of this value to the normal force of $1.96 \mathrm{~N}$ is 0.163 . This value should not be considered a friction coefficient but rather a scratching coefficient. The distribution of values suggests that it is other than random, yet it is more skewed to higher values than centered on the mean.

\section{Table A2.5.}

Summary of Scratch Tests on Polished Sections of Rotor and Pad Materials (200 gf load, diamond indenter $200 \mu \mathrm{m}$ radius tip, two or more scratches per specimen)

\begin{tabular}{|l|c|c|c|}
\hline \multicolumn{1}{|c|}{ Specimen } & Number of Data & $\begin{array}{c}\text { Average } \mathbf{F}_{\mathbf{t}} \\
(\mathrm{N})\end{array}$ & $\begin{array}{c}\text { Std. Dev. in } \mathbf{F}_{\mathbf{t}} \\
(\mathrm{N})\end{array}$ \\
\hline \hline cast iron rotor & 143 & 0.215 & 0.024 \\
\hline brake pad & 182 & 0.394 & 0.215 \\
\hline
\end{tabular}

A photomicrograph of one of the scratches in the cast iron rotor is shown in Fig. A2.7. Care examination of the scratches indicates that the hard indenter can cause graphite either to be extruded out to the side from its location within the iron matrix and retain the shape of tiny platelets, or it can be extruded directly into the scratch path and be smeared along the it. The lower standard deviation of tangential force for the rotor material suggests that the graphite may be lubricating the contact surface to some extent, even though it does not cover the surface completely.

\section{Figure Captions}

A2.1 Unetched polished section of a cast iron rotor showing the characteristics graphite flake morphology.

A2.2 Surface roughness data. (a) Outboard face of a rotor run against Type "OO" pad material, (b) Inboard face of the rotor surface (a), (c) Outboard face of a rotor run against Type "J" material, (d) Inboard face of the rotor surface (c).

A2.3 Photomicrograph of a polished brake pad Type "OO" showing its complex microstructure. There were no obvious differences in appearance between it and Type "J".

A2.4 Photomicrograph of an extraction of loosely-held pad surface particles.

A2.5 Typical chart recorder trace of scratching force (a) polished rotor (left) and pad (right). (b) digitized trace of the trace on the rotor.

A2.6. The frequency distributions of tangential force data for scratch tests are shown in (a) for the rotor and (b) for the disc material type "OO."

A2.7. Optical photomicrograph of one of the scratches in the cast iron rotor indicating extrusion of the graphite flakes. 


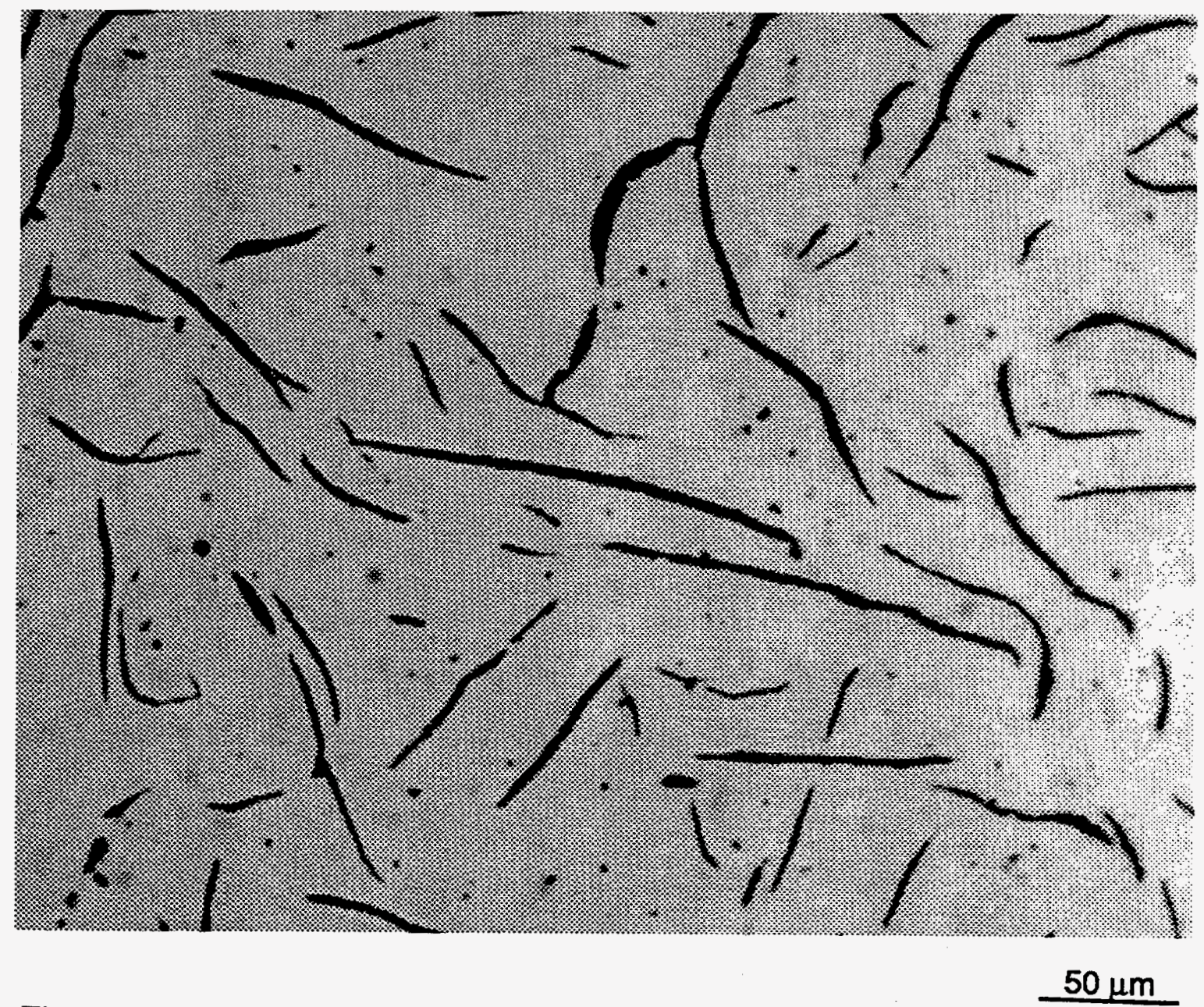

Figure A2.1 


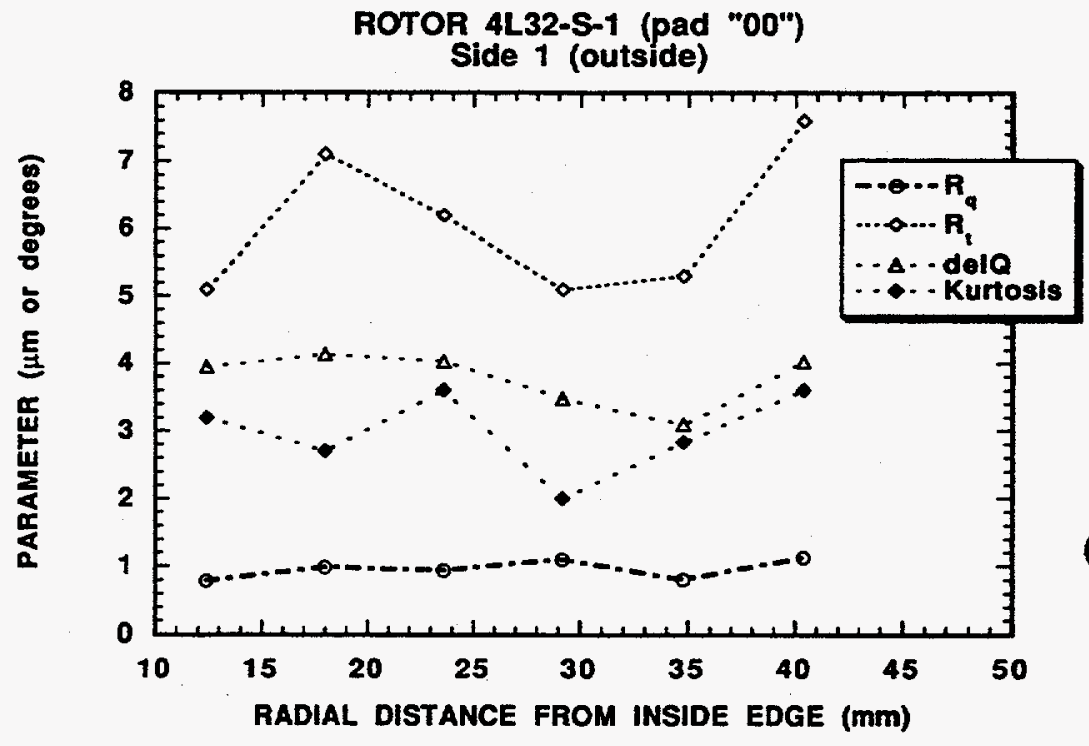

(a)

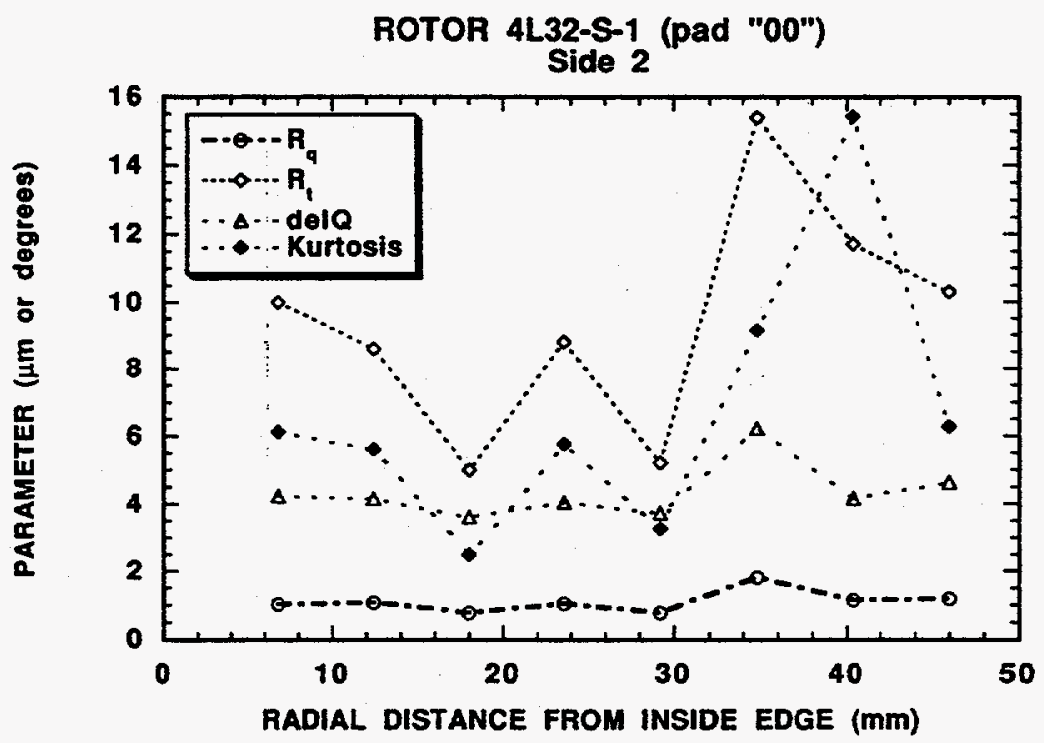

(b)

Figure A2.2 


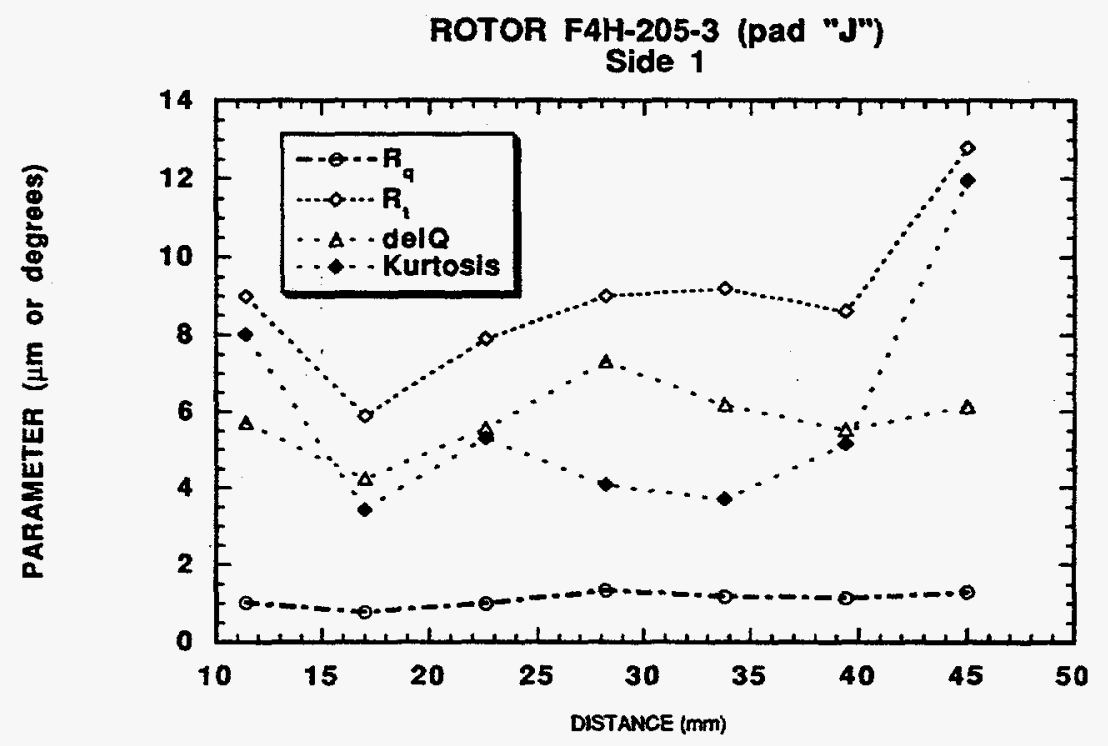

(c)

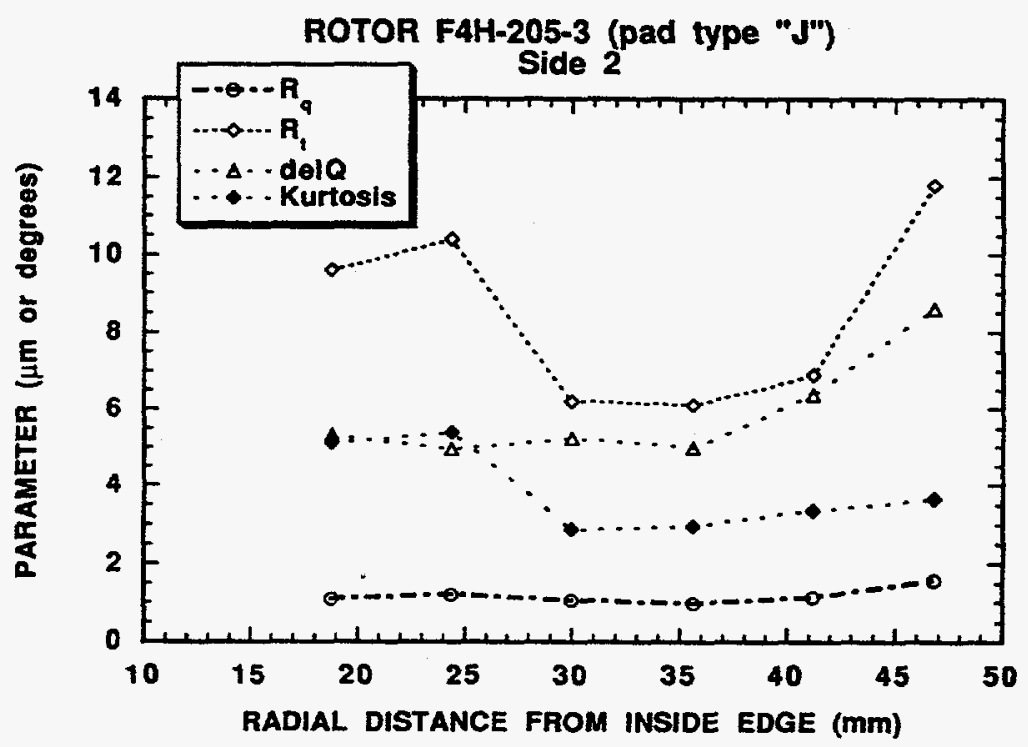

(d)

Figure A2.2 


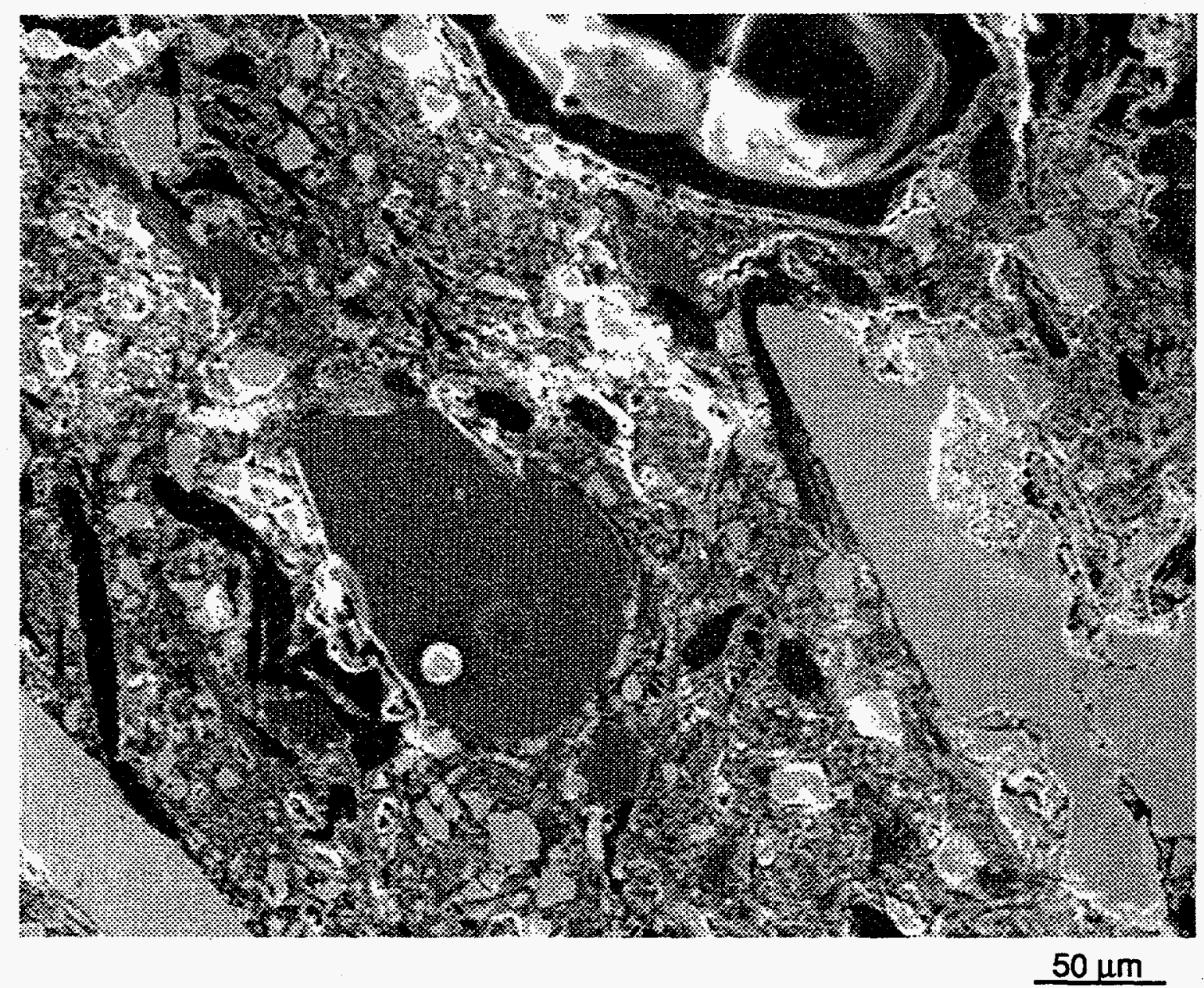

Figure A2.3 


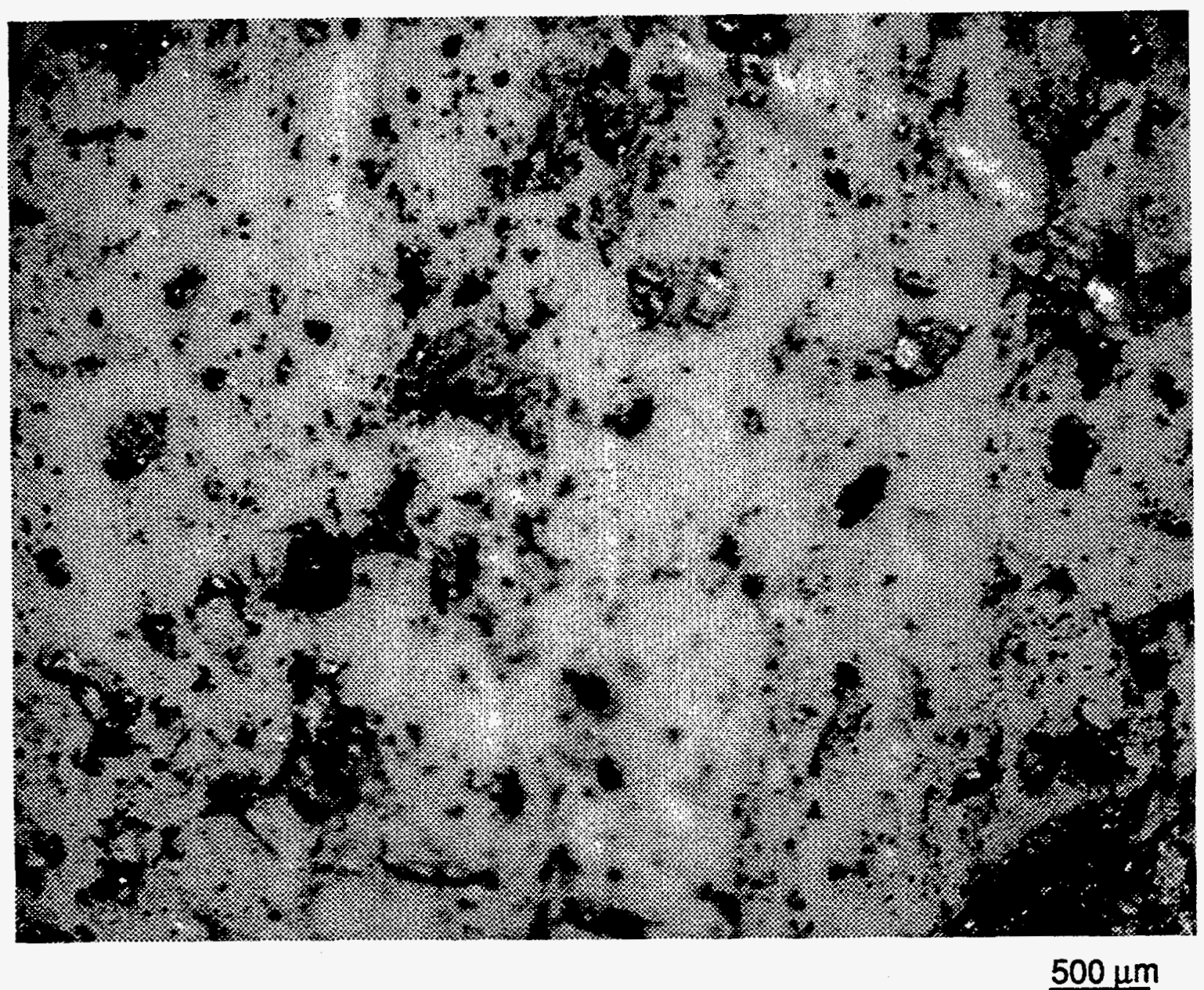

Figure A2.4 

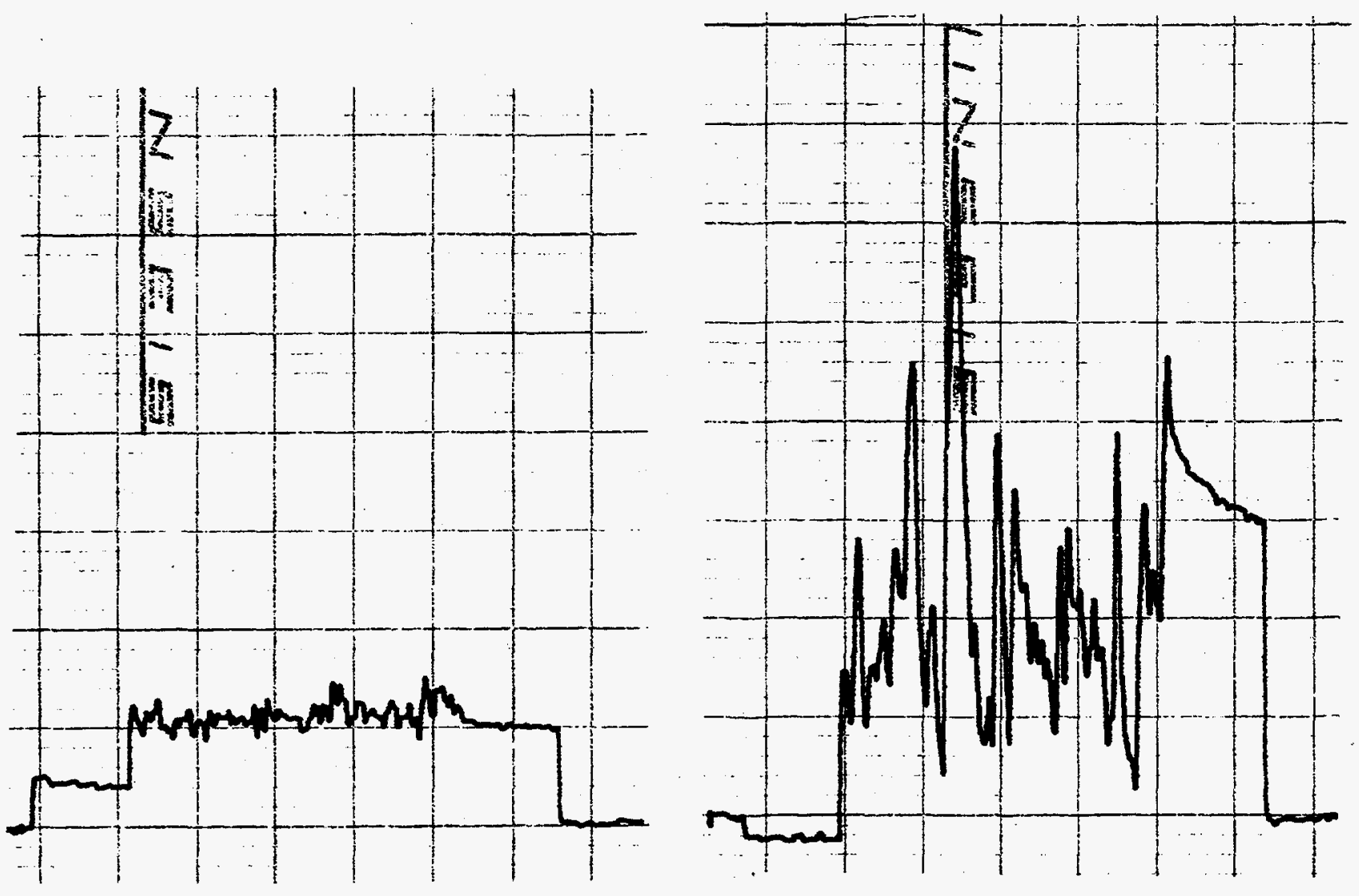

(a)

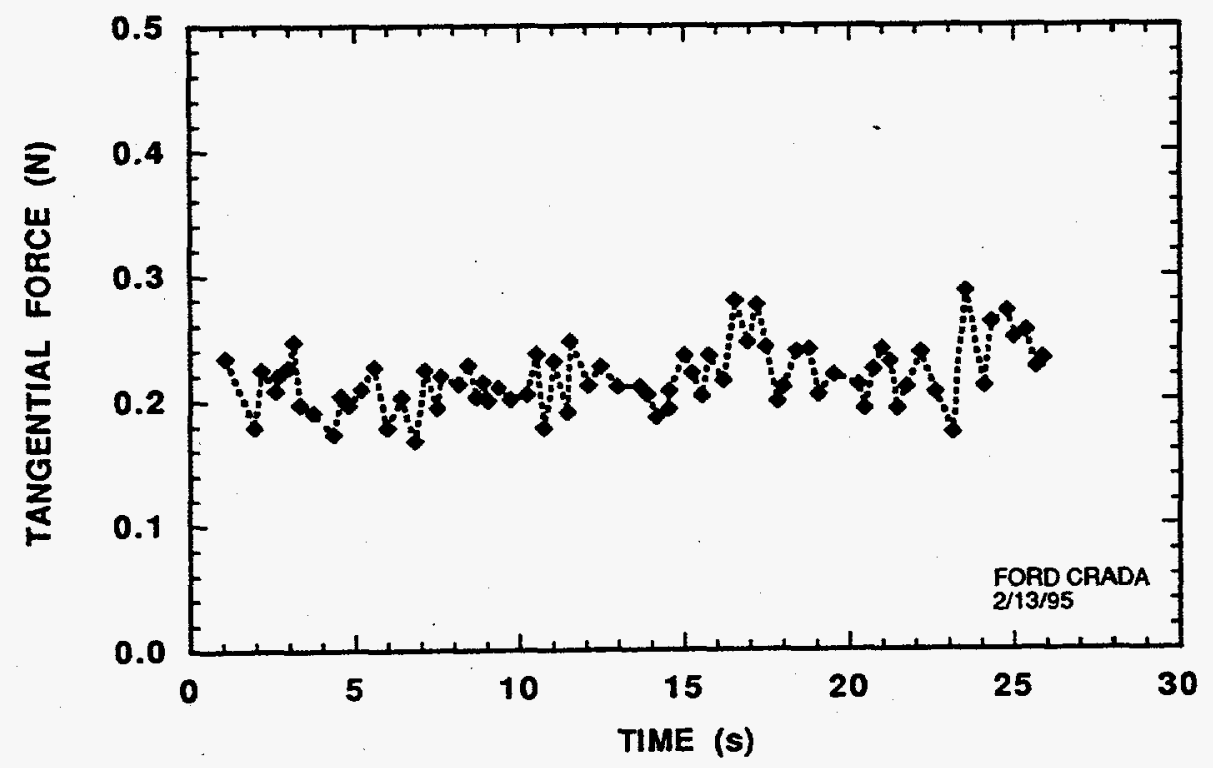

Figure A2.5

(b) 


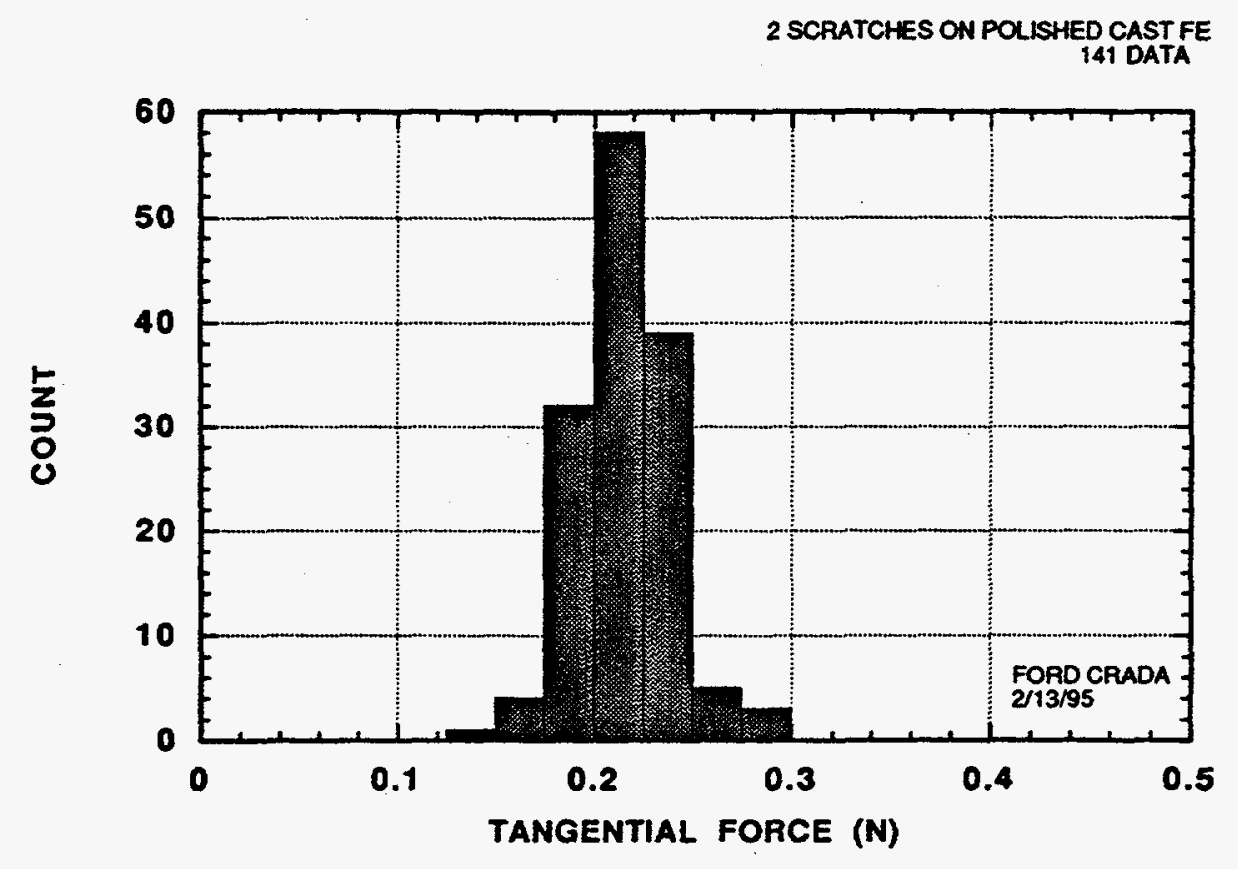

(a)

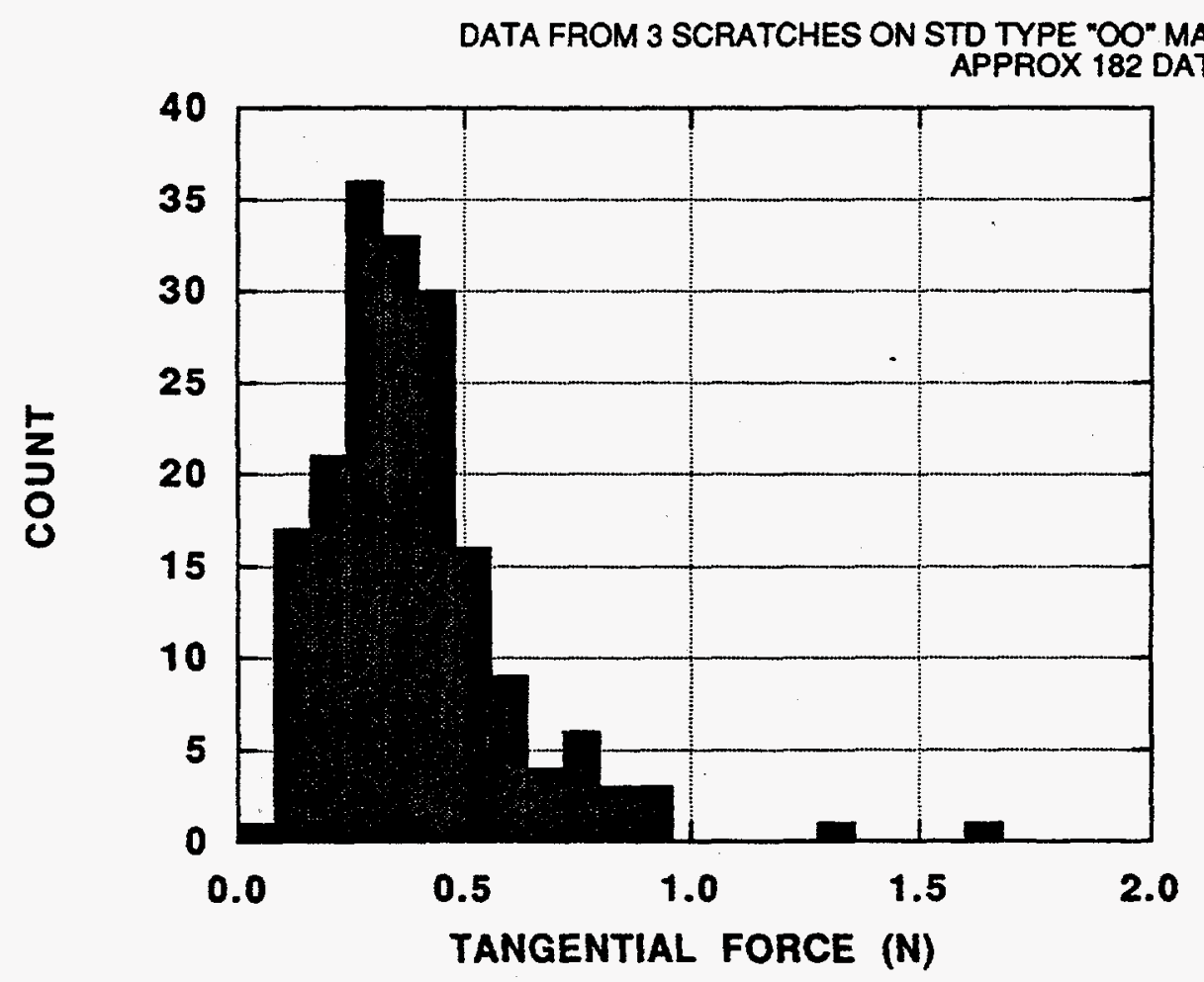

(b)

Figure A2.6 


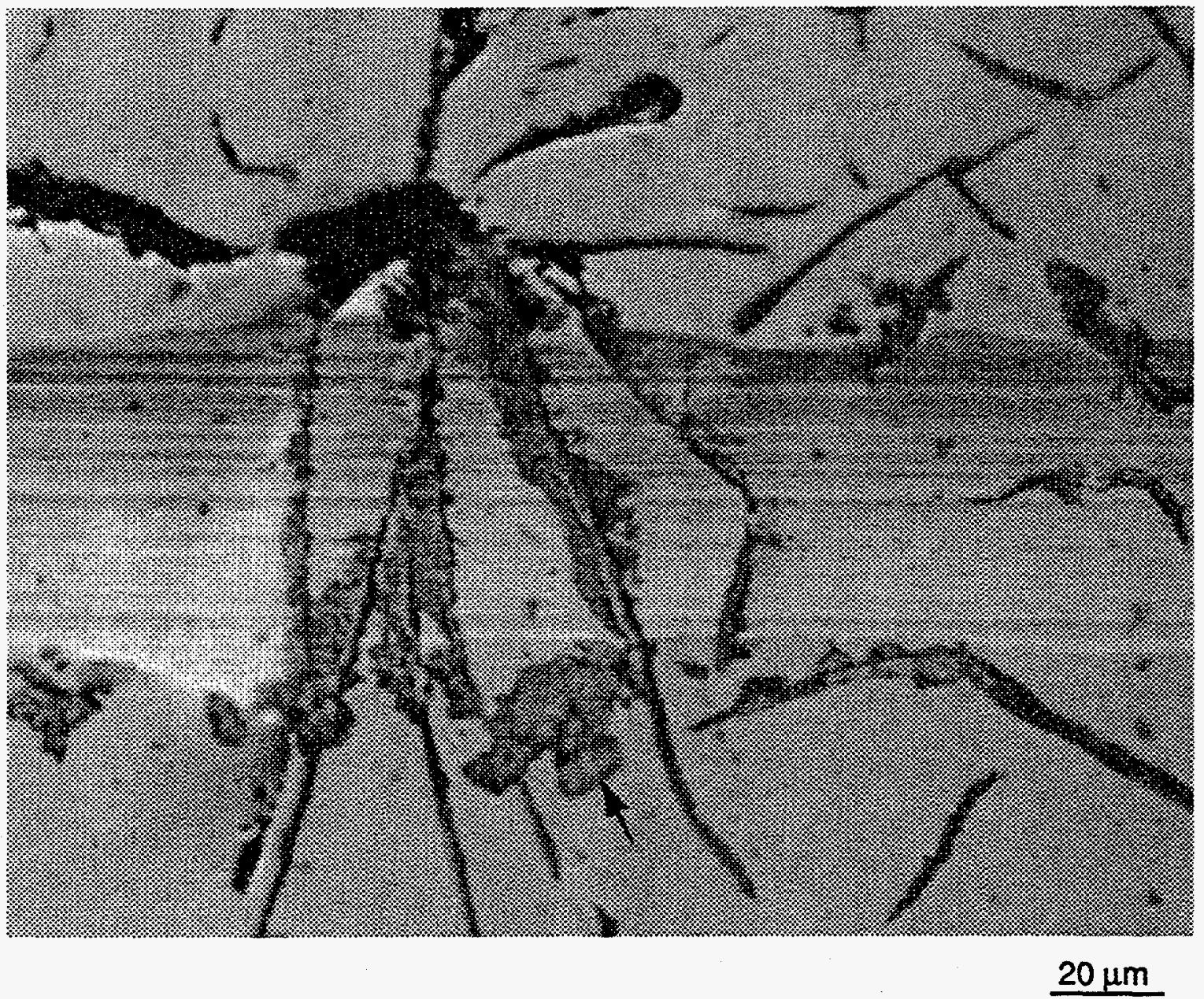

Figure A2.7 


\section{DISTRIBUTION LIST}

1-10. P. J. Blau

11. D. F. Craig

12. R. Dinwiddie

13. L. B. Dunlop

14. C. Hubbard

15. A. E. Pasto
16-17. T. Rosseel

18. A. C. Schaffhasuer

19. R. Ziegler

20. Central Research Library

21. Document Reference Section

22-25. Laboratory Records

26. Laboratory Records (RC)

27. ORNL Patent Office

28. Arnold E. Anderson, Tribo-Diagnostics, 30220 Rosemond Drive, Franklin, MI 48025

29. Russell J. Armer, Brakepro, Inc., 101 Friction Drive, Cartersville, GA 30120

30. William Donlon, Ford Motor Company, Scientific Research Lab., MD 3182, P. O. Box 2053, Dearborn, MI 48121-2053

31-33. James W. Fash, Ford Motor Company, Scientific Research Lab., MD 3182, P. O. Box 2053, Dearborn, MI 48121-2053

34. Charles W. Greening, Greening, Inc., 19465 Mt. Elliot Avenue, Detroit, MI 48234

35. Rena Hecht, Ford Motor Company, Scientific Research Lab., MD 3182, P. O. Box 2053, Dearborn, MI 48121-2053

36. Khalid Lafdi, Materials Technology Center, Mail Code 4303, Southern Illinois University at Carbondale, Carbondale, IL 62901-4303

37. Alex C. Lee, GM Delphi, Engineering Tech. Center, P. O. Box 1245 (MS E-521), Dayton, OH 45401.

38. Roy H. Link, Link Engineering, Inc., 43855 Plymouth Oaks Blvd., Plymouth, MI 481702585

39. David T. Marx, Materials Technology Center, Mail Code 4303, Southern Illinois University at Carbondale, Carbondale, Ill 62901-4303

40. Stephen H. Morgan, Akebono America, Inc., 26850 Haggerty Road, Farmington Hills, MI 48331

41. Allan Taub, Ford Motor Company, Scientific Research Lab., MD 3182, P. O. Box 2053, Dearborn, MI 48121-2053

42. Steven F. Wyss, Ferodo America, Inc., 1 Grizzly Lane, Smithville, TN 37166

43. Yongbin Yuan, ABEX Friction Products, P. O. Box 3250, Winchester, VA 22601-2450

44-45. U.S. DOE, Office of Scientific and Technical Information, P. O. Box 62, Oak Ridge, TN 37831 